
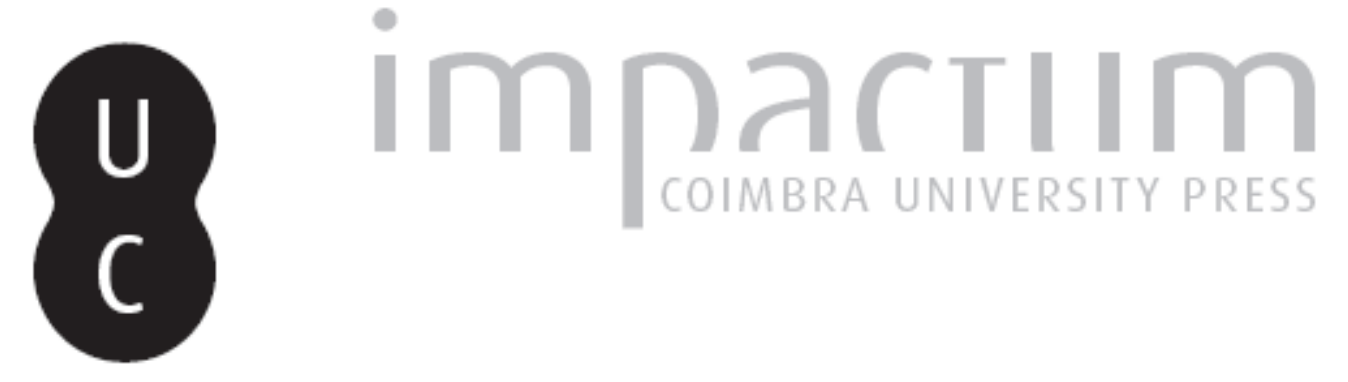

\title{
Movimentos de vertente na área de Peso da Régua: análise e avaliação multicritério para o zonamento de hazards em ambiente SIG
}

Autor(es): $\quad$ Santos, J. G.

Publicado por: Associação Portuguesa de Riscos, Prevenção e Segurança

URL

persistente:

URI:http://hdl.handle.net/10316.2/40086

DOI:

DOI:https://doi.org/10.14195/1647-7723_9_4

Accessed : $\quad$ 26-Apr-2023 07:40:23

A navegação consulta e descarregamento dos títulos inseridos nas Bibliotecas Digitais UC Digitalis, UC Pombalina e UC Impactum, pressupõem a aceitação plena e sem reservas dos Termos e Condições de Uso destas Bibliotecas Digitais, disponíveis em https://digitalis.uc.pt/pt-pt/termos.

Conforme exposto nos referidos Termos e Condições de Uso, o descarregamento de títulos de acesso restrito requer uma licença válida de autorização devendo o utilizador aceder ao(s) documento(s) a partir de um endereço de IP da instituição detentora da supramencionada licença.

Ao utilizador é apenas permitido o descarregamento para uso pessoal, pelo que o emprego do(s) título(s) descarregado(s) para outro fim, designadamente comercial, carece de autorização do respetivo autor ou editor da obra.

Na medida em que todas as obras da UC Digitalis se encontram protegidas pelo Código do Direito de Autor e Direitos Conexos e demais legislação aplicável, toda a cópia, parcial ou total, deste documento, nos casos em que é legalmente admitida, deverá conter ou fazer-se acompanhar por este aviso.

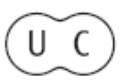




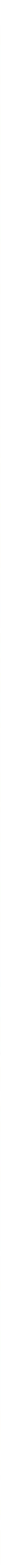




\title{
Movimentos de vertente na área de Peso da Régua; análise e avaliação multicritério para o zonamento de hazards em ambiente SIG
}

\author{
J. G. Santos*
}

\begin{abstract}
Resumo:
O propósito matricial do presente estudo consiste no ensaio de uma metodologia de análise e avaliação multicritério para a cartografia automática dos movimentos de vertente em ambiente SIG, partindo da sua identificação, inventariação e classificação. Na sequência do contex to meteorológico excepcional que caracterizou o Outono-Inverno de $2000-200 \mathrm{I}$ em Portugal, a frequência, a magnitude e, em pelo menos duas situações, a violência com que alguns desses movimentos afectaram as vertentes da bacia do Douro na área da Régua, envolvendo elevados danos materiais e a perda de vidas humanas, mostram a importância aplicada do ensaio metodológico que se apresenta.

Palavras-chave:

Movimentos de vertente, susceptibilidades, hazard, vulnerabilidade e risco
\end{abstract}

\section{Résumé:}

Cet étude prétend essayer une méthodologie d'analyse etévalution multicritère pour la carthographie automatique des mouvementes de versant dans une ambience SIG en partant de son identification, inventoration et classification. Suite à la situation météo exceptionnelle qui a caractérisé l'Automne-Hiver 2000-2001 au Portugal, la fréquence, la magnitude et, au moins en deux cas, la violence de ces mouvements sur les versants du bassin du Douro, à Régua, a provoquée de nombreux dégâts et la perte de vies humaines, d'où l'importance appliquée de cet éssai méthodologique.

Mots clés:

Mouvements de versant, susceptibilités, aléas, vulnerabilité, risque.

\begin{abstract}
:
The present study aims to test a multicriteria evaluation methodology to produce landslide hazard GIS based maps; the investigations have started with the identification, recognition and classification of several examples of landslides. Consideration is given to their frequency, magnitude and in some cases to the catastrophic degree of loss, of life and goods, mainly near Régua - Douro basin, as the result of an extreme meteorological context of the portuguese Winter 2000-2001, and these were important contributions for the definition of the application area.
\end{abstract}

Key-words:

Landslide, hazard, susceptibilities, vulnerability and risk

\section{Introdução}

Identificados pela dinâmica gravítica ${ }^{(1)}$, conhecidos pelo espectro morfológico de pormenor com que moldam as vertentes e pelo depósito resultante da sua evolução, e reconhecidos pelos seus efeitos (por vezes) catastróficos, os desastres relacionados com a

* Instituto de Estudos Geográficos. Faculdade Letras. Universidade de Coimbra

(1) Os movimentos de vertente são processos gravíticos de onde são excluídos aqueles em que há intervenção de agentes (água, ar ou gelo) que exercem acções de transporte (HUTCHINSON, 1968, 1988; VARNES, 1978; BRUNSDEN 1984). No essencial esta ideia está também implícita na definição de Landslide proposta por CRUDEN (1991) para a WORKING PARTY ON WORLD LANDSLIDE INVENTORY (WP/WLI) referindo que se trata de um "movimento de material rochoso, coerente ou detrítico, ao longo da vertente em direcção à base". Não se faz referência aos mecanismos do movimento e, de algum modo, é um reformular do que havia já sido proposto por TERZAGHI (1952) referido em ZêZERE $(1997,2000)$. ocorrência de movimentos de vertente têm vindo a produzir impactes crescentes não tanto pelo também crescente número de registos mas principalmente pela frequência, magnitude e violência com que têm vindo a afectar as populações. Sendo importante, a leitura do quadro anterior não pode, no entanto, deixar de se enquadrar pelo aumento significativo da vulnerabilidade dos espaços (funcionalidades e infraestruturas) colocando em risco as gentes e os seus modos de vida e gerando efeitos amplificadores das dimensões das próprias catástrofes.

O âmbito local, mas relativamente generalizado, da ocorrência de movimentos de vertente tem vindo a preocupar entidades e motivar investigadores para a convergência de esforços no sentido da definição de redes de dados internacionais que permitam mitigar os seus efeitos. Deverão ter sido desta natureza as 
razões e princípios que estiveram na génese de vários projectos de investigação como, por exemplo, o "The Temporal Occurrence and Forecasting of Landslides in the Europeen Community" - EPOCH e o sucedâneo "The Temporal Stability and Activity of Landslides in Europe with Respect to Climate Change"-TESLEC ${ }^{(2)}$. Balizados por prazos contratuais restritos, 1991-93 e 1994-96, respectivamente, estes projectos sublinham a importância atribuída ao estudo destes fenómenos, com particular notoriedade ao longo da década de noventa, importância que é ainda notada e reconhecida pela criação da UN International Strategy for Disaster Reduction (ISDR) e de um grupo de trabalho da UNESCO - Working Party on World Landslide Inventory (WP/WLI), no âmbito da International Decade for Natural Disaster Reduction (IDNDR). Entre os resultados do trabalho que tem vindo a ser desenvolvido, destacamos o esforço e a consciência generalizados que apontam o sentido da transição de uma "cultura de reacção" para uma "cultura de prevenção", como mensagem e princípio fundamental da mitigação dos desastres naturais e caminho a seguir na prossecução do desenvolvimento sustentado e sustentável (ELO, IN SINGH, 1994).

\section{Localização da área}

A área em estudo localiza-se na transição do sector SW de Trás-os-Montes para as terras altas do

(2) Destacamos a obra intitulada "Landslide recognition. Identification, movement and causes", cujo carácter pensamos ser indiscutivelmente referencial e que, em jeito conclusivo deste projecto, viria a ser publicada em 1996, por DIKAU, BRUNSDEN, SCHROTT \& IBSEN. norte da Beira, que constituem o seu prolongamento geomorfológico para sul do Douro. Corresponde basicamente ao espaço abrangido pela folha 126 (Régua) da Carta Militar de Portugal, com escala $1 / 25000$ (fig. 1). O Rio Douro, elemento dominante da paisagem, definiu profundos encaixes entre os íngremes contrafortes orientais e meridionais da Serra do Marão (na margem direita) e o sector norte da Serra de Montemuro (na margem esquerda), traços fundamentais da reorganização quaternária da sua rede hidrográfica. Numa primeira análise, a ausência de depósitos e as profundas gargantas, com rápidos e cachões que caracterizam este sector do vale do Douro levam a pensar que fenómenos antecedentes estiveram na origem e na definição do actual traçado do vale; no entanto, uma leitura mais atenta da estrutura do relevo não deixa de dar alguma força à tectónica de fracturação pelo que, no pormenor, a morfologia do vale do Douro, nesta área, parece dever-se mais ao rejogo quaternário de acidentes antigos, alguns dos quais com características de desligamento, em geral esquerdo, num quadro de capturas sucessivas que denunciam a adaptação à rede de fracturação.

No quadro geo-humano não pode deixar de se destacar a importância dos recursos, designadamente a vinha e o Vinho do Porto, e as suas influências na paisagem e nos modos de vida das populações. Vulneráveis à violência das cheias com que o rio continua a fustigar as edificações ribeirinhas, mesmo depois de controlado pela tecnologia das muitas barragens e albufeiras portuguesas e espanholas, as populações têm vindo a procurar refúgio ao longo das vertentes do vale, criando assim novas vulnerabilidades.

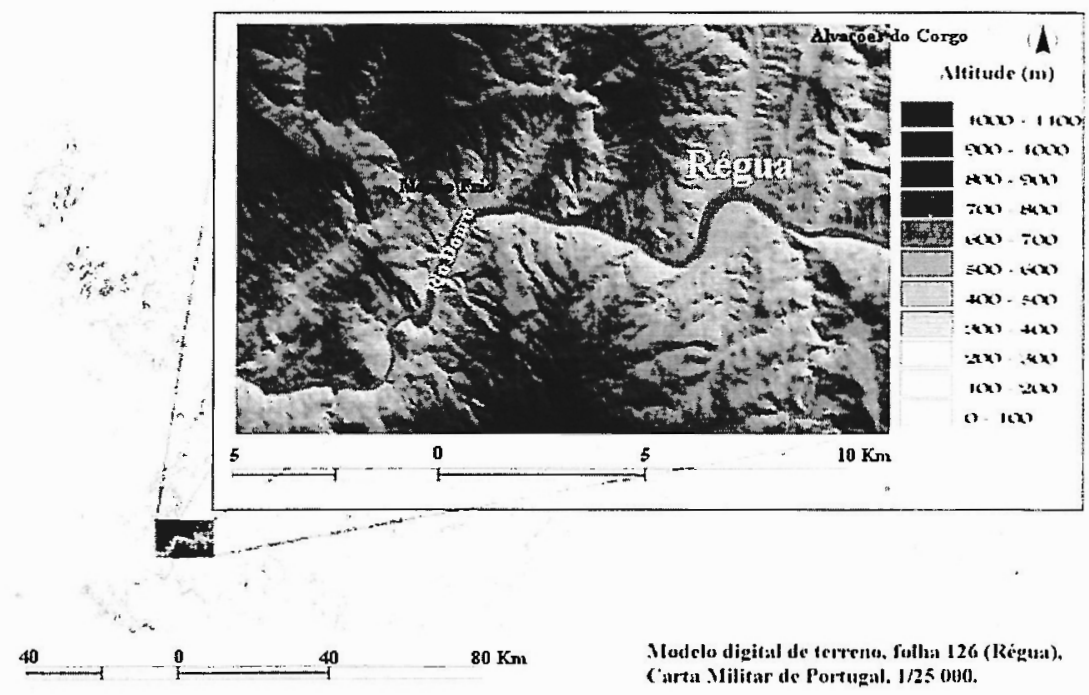

Fig. 1- Localização da área em estudo. (Modelo digital de terreno elaborado com base na folha 126 (Régua) da Carta Militar de Portugal, 1/25 000, [GeoE, adaptado). 


\section{Referências, propósitos do trabalho e meto- dologias utilizadas}

A estabilidade de uma vertente depende do jogo de forças que se estabelece entre dois grandes conjuntos de factores definindo, assim, um balanço ou relação que designamos por "relação de equilíbrio dinâmico ou princípio de estabilidade das vertentes" (fig. 2).

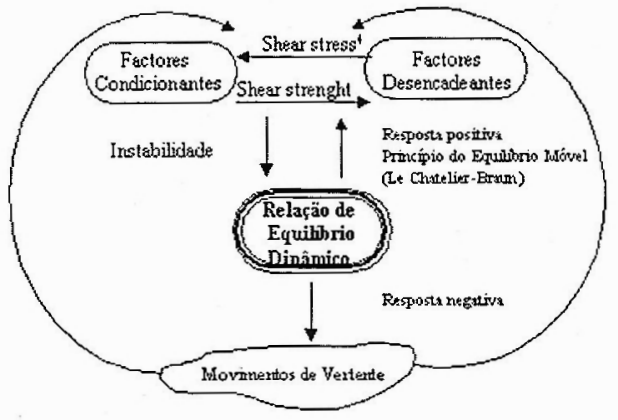

Fig. 2 - Relação de equilíbrio ou Princípio de estabilidade das vertentes.

Esta relação, antes de mais, define um estado ou, se preferirmos, uma sucessão de estados morfodinâmicos da vertente que se traduzem pela tendência natural a conservar ou a recuperar as condições de estabilidade. Resulta do confronto entre factores condicionantes e factores desencadeantes (ZêZERE, 2001); no primeiro grupo de factores referido estão incluídos os factores estruturais e morfológicos, por vezes, também referidos como factores intrínsecos ao material rochoso ou à vertente, cuja dinâmica concorre para a evolução da vertente no sentido da dissipação das condições de stress - shear strenght (HANSEN, 1984) de modo a garantir novas (mas diferentes) condições de equilíbrio. O segundo grupo de factores, em regra, está associado a aspectos de natureza climática, hidro-climática, sísmica, mas também antrópica; são também referidos na literatura como factores extrínsecos (TERZAGHI,
1950, referido por BRUNSDEN \& PRIOR, 1984; FERRER-GIJóN, 1987) e, por ser responsável pela introdução de variáveis exógenas nos sistemas-vertente a segunda das categorias de factores referida está, por isso, na génese das condições de instabilidade shear stress, que poderão fazer evoluir a vertente no sentido da sua movimentação total ou parcial.

Facilmente reconhecidas pelas marcas que deixam na paisagem, as manifestações de instabilidade nas vertentes ameaçam as populações, seja pela afectação do normal decurso das suas actividades, seja porque colocam em perigo as suas próprias vidas. O grau de exposição dos diversos elementos infra-estruturais de um território e a vulnerabilidade específica de cada um desses elementos contribuem para a definição de um coeficiente de risco que caracteriza cada um desses espaços; noâmbito dos movimentos de vertente, o cálculo dos valores que este coeficiente pode assumir é função do produto da probabilidade de ocorrência de um movimento susceptível de produzir danos significativos num ou mais elementos de um território, pela vulnerabilidade dos diferentes espaços (C. VAN WESTEN, 1998). Neste contexto, pensamos que as tarefas de hazard ${ }^{(3)}$ e risk assessment (fig. 3), na sua componente predictiva, implicam uma abordagem que nãopode deixar de ligar as componentes

(3.) Utilizamos o termo hazard devido às muitas dificuldades em encontrar equivalente conceptual na língua portuguesa; com o mesmo sentido, alguns autores utilizam o conceito de "susceptibilidade" (TAVARES, 1999) enquanto outros como ZêZERE E RODRIGUES (1991), ZêZERE (1997, 2001) preferem a expressão "perigosidade"; jâ BATEIRA (2001) referindo as muitas dificuldades em adaptar o termo hazard à língua portuguesa prefere a expressão "eventualidade". que segundo o Autor envolve já o carácter fortuito da probabilidade e, por outro lado, o "eventum" ou acontecimento, acidente. Aplicada ao estudo da instabilidade das vertentes, a noção de "perigosidade" prevê a componente probabilidade de ocorência de um evento perigoso, no espaço e no tempo. A sua utilização em estudos de geomorfologia é frequente e, geralmente aceite, mas quando utilizado como tradução de hazard a questão deixa de reunir consenso, na medida em que de acordo com REBELO (1997), tanto a ideia de "perigo" como a de "risco" podem estar presentes. O conceito de hazard utilizado pela UN Working Party on World Landslide Inventory (WP/WLI) inclui a probabilidade de ocorrência de um dado fenómeno potencialmente danoso, no espaço e no tempo, e a descrição e caracterização das formas e mecanismos envolvidos. Por outro lado, entendemos que a noção de
Fig. 3 - Elementos da cadeia multivariada para análise, avaliação e cartografia do risco de ocorrência de movimentos de vertente.

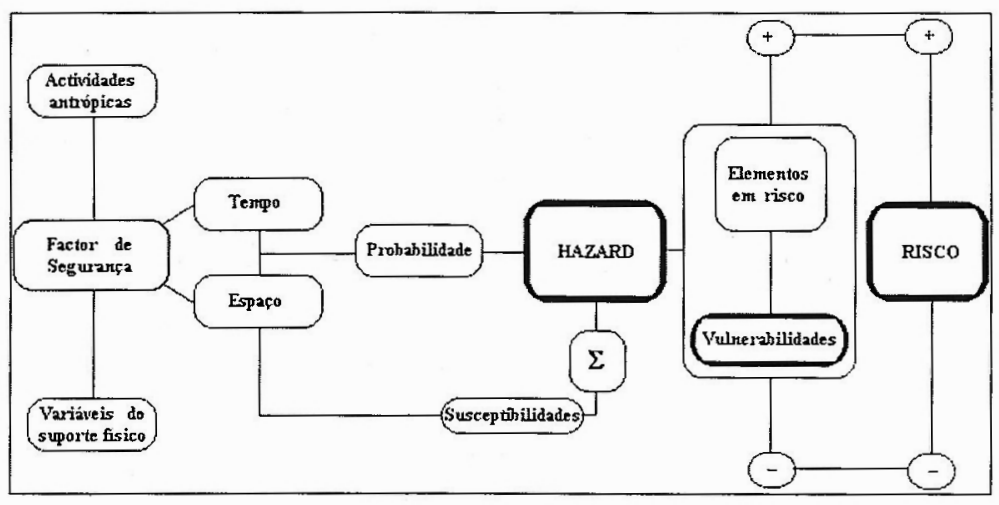


tempo e espaço; nesta medida, concordamos com ZÊZERE (2001) quando refere que o aspecto temporal da previsibilidade só pode ser resolvido pelo conhecimento do mecanismo do movimento de vertente e do período de recorrência dos respectivos factores desencadeantes, e que só o recurso à cartografia pode ajudar a encontrar soluções, relativamente à componente espacial. Referidos na mesma obra, GUEREMY (1984), ASTÉ(1991) e SOETERS \& VAN WESTEN (1996) propõem que, à escala regional, as tarefas de avaliação de hazards se devem realizar em três etapas:

a) inventário e análise das manifestações de instabilidade que já se verificaram no território;

b) identificação dos factores condicionantes e desencadeantes responsáveis pelo aparecimento ou aceleração dos movimentos;

c) interpretaçãodos factores, implementando modelos de correlação espacial directos ou indirectos.

Seguindo de muito perto o enquadramento metodológico anteriormente apresentado, procurámos adaptar a informação que desde Janeiro de 2001 temos vindo a recolher relativamente aos movimentos de vertente que afectaram inúmeras vertentes na bacia do Douro, alguns dos quais com carácter verdadeiramente catastrófico pelos danos e mortes que originaram (fig. 4). Partindo da cartografia sistemática, no terreno, de todos os movimentos de vertente ${ }^{(4)}$ que apresentassem uma área afectada igual ou superior a $9 \mathrm{~m}^{2}$ e/ou um volume (estimado) de material movimentado igual ou superior a $1 \mathrm{~m}^{3}$, os movimentos foram classificados em três categorias (grau 1-G1, grau 2-G2 e grau 3-G3), em função de

\footnotetext{
"susceptibilidade" tem uma conotação temática, com identidade espacial definida, ou seja, fala-se com frequência em susceptibilidade lítica, morfológica, etc, pelo que pensamos ser até mais correcto utilizar o plural (susceptibilidades). Neste sentido, só quando complementado com informação que inclua a componente "tempo", o somatório dinâmico das várias susceptibilidades de uma vertente a um mecanismo ou conjunto de mecanismos que podem conduzir à sua movimentação total ou parcial, se pode aproximar do conceito de hazard. Quandoentendidonesta perspectiva, que concorda com o proposto por BRABB ET AL. (1972), referidos por EINSTEIN (1997) e que está também explícita em HAMILTON (1997), os dois conceitos acabam por se confundir, e aplicar em situações semelhantes. Por não existir consenso entre os diversos investigadores, optamos por não adoptar (como tradução de hazard) qualquer dos termos referidos ou mesmo introduzir um outro, o que em nosso entender levaria a um acréscimo de confusão terminológica; assumimos, antes, que nos preocupa mais o facto de procurar conservar o significado conceptual de hazard, cuja utilização deverá ser sempre lida no sentido que lhe é atribuído pela WL/WLI, e que os termos "susceptibilidade" e "perigosidade" serão utilizados com o sentido que lhes é geralmente atribuído na literatura lusógrafa.

(4) Identificámos 441 movimentos de vertente, que foram cartografados de modo sistemático. Procurámos definir os percursos de modo a assegurar uma variabilidade representativa, dos pontos de vista lítico, morfológicoe também da ocupação e uso do solo; deste modo, para além das principais estradas e outras vias secundárias percorridas seleccionámos ainda alguns caminhos rurais. $O$ registo cartográfico dos movimentos de vertente foi efectuado sobre a folha 126 (Régua) da Carta Militar de Portugal à escala $1 / 25000$.
}

parâmetros morfométricos ${ }^{(5)}$ como a dimensão longitudinal e a área afectada, e morfodinâmicos como a tipologia do(s) mecanismo(s) envolvido(s) e a actividade (estilo, estado e distribuição espacial). Em fase posterior do trabalho, procurámos relacionar a distribuição de cada um dos tipos de movimentos definidos em função do perigo potencial que representam, com as condicionantes hidrográficas, estruturais e morfológicas, parametrizáveis, que julgámos serem importantes para a compreensão das causas que estiveram na génese das condições de ocorrência dos movimentos de vertente, mas acima de tudo, na definição de um padrão que caracteriza a sua localização e distribuição espaciais.

Um exercício análogo, levou-nos a prosseguir a investigação tendo como meta identificar os factores desencadeantes dos movimentos de vertente. Efectuada esta análise procedemos à elaboração de um modelo de correlação espacial que consistiu na definição de uma fórmula de cálculo (SANTOS, CUNHA \& FERREIRA, em publicação) para atribuição de pesos específicos a cada uma das sub-classes dos diversos factores condicionantes analisados. Foram atribuídos pesos específicos a cada um dos factores, e dentro de cada um deles, quando foi possível proceder a uma subdivisão interna como, por exemplo, no caso dos declives, sempre que as diferentes classes surgiram com diferentes valores de associação com a distribuição dos movimentos de vertente, optámos por atribuir pesos diferenciados também dentro do mesmo factor. O exemplo da distribuição dos três tipos de movimentos de vertente relativamente aos declives, já referido, permitiu relacionar com cada uma das nove classes consideradas $\left(0-8^{\circ}, \ldots, 64-72^{\circ}\right)$ evidenciando diferentes graus de associação entre as duas variáveis; assim, por exemplo, os declives compreendidos entre $16 \mathrm{e}$ $24^{\circ}$ surgem associados a $26 \%$ dos movimentos do tipo G1 40\% de G2 e $15 \%$ de G3; os pesos atribuídos, neste caso, foram " 3 ", " 5 " e " 2 ", respectivamente. Este procedimento, iterativo, repetiu-se na análise dos restantes factores (e sub-classes) considerados. Assim, o cálculo, por processo automático, de um

\footnotetext{
(5) Em função do perigo potencial que associámos aos movimentos de vertente identificados procedemos ao seu agrupamento em três categorias: G1 - pequenos desabamentos ou deslizamentos rotacionais de estilo simpies, com dimensāo longitudinal métrica, extremamentetápidos, geralmente activos, e com distribuição da actividade segundo uma dinâmica em avanço.

G2 - pequenos desabamentos ou deslizamentos rotacionais, simples ou conjugados com pequenos fluxos de lama, terra ou detritos, saturados, com dimensão longitudinal decamétrica, muito rápidos a extremamente rápidos e com distribuição da actividade segundo uma dinâmica em avanço G3 - desabamentos, deslizamentos rotacionais ou translacionais conjugados com fluxos de lama, terra ou detritos, com dimensão longitudinal hectométrica, muito rápidos a extremamente rápidos; movimentos activos que podem apresentar um estilo múltiplo e variações sensíveis na distribuição da actividade que pode definir uma dinâmica em avanço, retrogressiva ou progressão múltipla; aproveitam quase sempre o traçado de pequenos canais geralmente inactivos.
} 

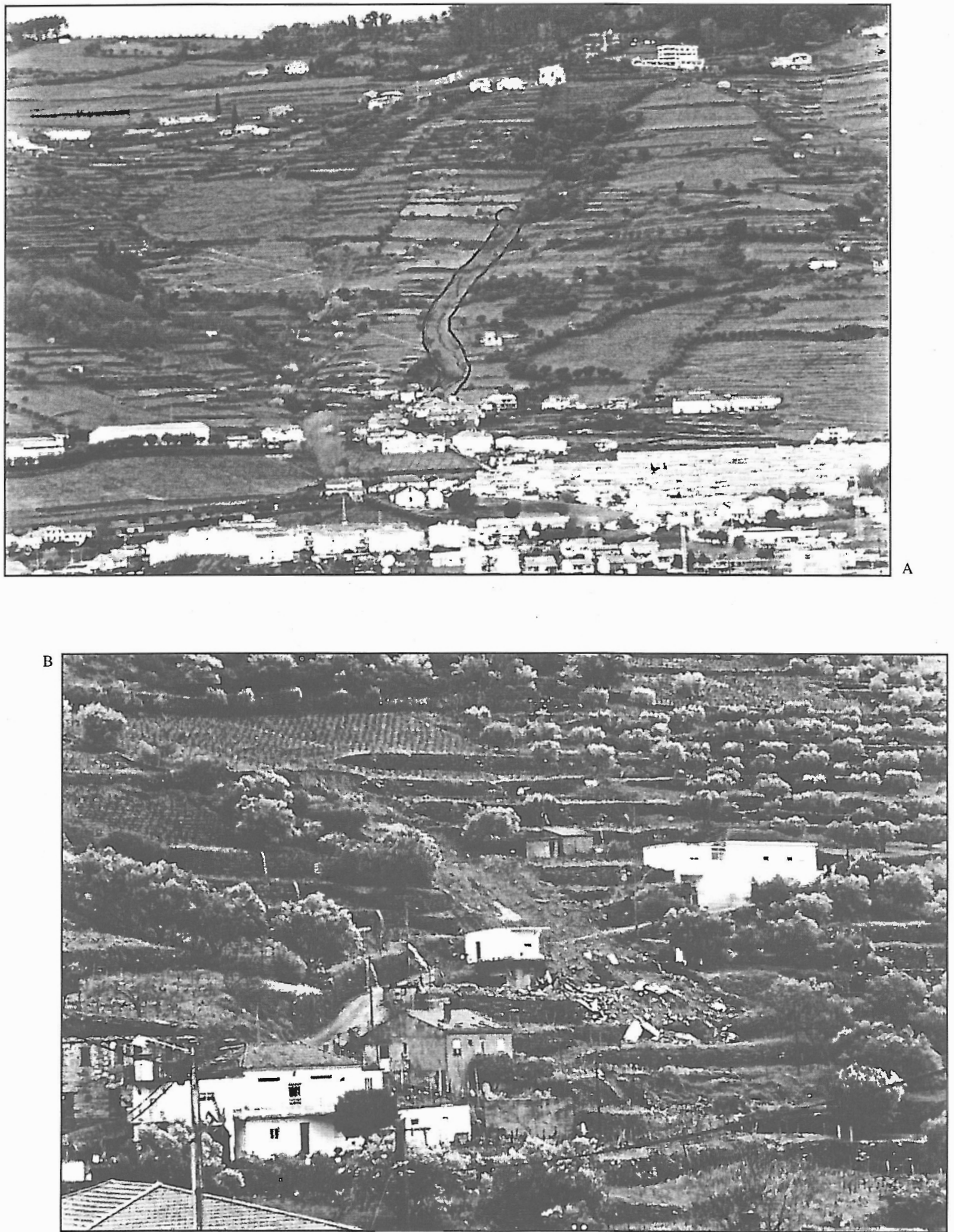

Fig.4 - Movimentos de vertente catastróficos; A - Lugar de Ariz (Godim-Régua);

B - Lugar de Azinheira (Alvações do Corgo-Sta. M. Penaguião). 
valor de hazard $(\mathrm{Hz})$ relativo a cada tipologia de movimentos de vertente (G1, G2 ou G3) resultou do somatório da décima parte inteira (peso específico da variável ou classe da variável) da frequência de distribuição(rl) de uma dada tipologia de movimentos $\left(G_{i}\right)$ pelas classes (quando existentes) da variável $V_{j}$, o que pode ser traduzido segundo a expressão,

$$
\mathrm{Hz}=\sum\left(\mathrm{r} 1\left(\mathrm{G}_{\mathrm{i}}\right) / 10\right)\left(\mathrm{V}_{\mathrm{j}}\right)
$$

Em função dos resultados numéricos obtidos, optámos por uma classificação segundo o processo que o sistema designa por natural breaks do qual resultam classes com diferentes amplitudes. Os valores obtidos foram posteriormente convertidos em dados qualitativos como "fraco", "moderado" e "forte" que permitiramozonamento da probabilidade de ocorrência de um dado tipo de movimentos:

0-46, Fraca probabilidade de ocorrência 46-76, Fraca a moderada probabilidade de ocorrência 77-102, Moderada probabilidade de ocorrência 103-134, Moderada a forte probabilidade de ocorrência

135-165, Forte probabilidade de ocorrência

A diferenciação dos pesos específicos atribuídos, efectuada em função do conhecimento qualitativo da área, é quase sempre subjectiva seja qual for a metodologia utilizada. Pensamos que a subjectividade estará sempre presente até porque, como referem BROMHEAD \& IBSEN (1997), os factores envolvidos não são necessariamente independentes nem constantes no tempo. No entanto, esta metodologia permite uma análise coerente da importância de cada um desses factores, considerados individualmente mas sobretudo na dependência de um quadro interactivo e interdinâmico de variáveis. Quando comparadas com outros modelos quantitativos para estimar a probabilidade de ocorrência de movimentos de vertente, MOSTYN \& FELL(1997) referem mesmo que estas metodologias devem ser encaradas com igual valor científico. Reconhecida por vários autores (ROBERDS, HO \& LEUNG, 1997; MOSTYN \& FELL (1997), entre outros, a importância destas metodologias de base quantitativa com ponderação factorial empírica, reside nos resultados obtidos em função das múltiplas correlações estabelecidas entre parâmetros de input e de output. Queremos, no entanto, salientar que se trata apenas de uma das possíveis metodologias para avaliação e cartografia de hazards, e que a abordagem às questões do ordenamento do território implica, necessariamente, uma diversidade de escalas de análise. Impõe-se, por isso, a convergência no sentido da complementaridade, que ao nível da cartografia se traduz pela articulação de informação de "espaço longo", "intermédio" e "curto", o que concorda com as conclusões apresentadas por BARREDO, BENAVIDES, HERVáS, LOMOSCHITZ \& VAN WESTEN (2000). Foi com base na fórmula anteriormente referida que se ensaiou o zonamento das áreas com exposição diferencial à ocorrência de movimentos do tipo G1, G2 e G3, construindo mapas que designámos por "mapas intercalares". $\mathrm{Da}$ ponderação destes três mapas em função dos danos que cada uma destas tipologias de movimentos pode produzir a jusante ${ }^{(6)}$, resultou a elaboração de um mapa que designámos por Mapa-síntese de hazards.

\section{Factores condicionantes}

Não tendo sido possível obter informação mais recente e de maior pormenor sobre a litologia da área em estudo, optou-se pela utilização da informação disponibilizada pela folha 10-C da Carta Geológica de Portugal, 1/50000. Depois de rasterizada foi trabalhada em formato de imagem e serviu de base para a construção de um tema poligonal que transformou a litologia num layer vectorial, posteriormente submetido a um processo de georreferenciação em ambiente ArcView. A informação obtida foi complementada pelos dados resultantes das diversas observações de campo, designadamente com dados relativos ao registo sedimentar quaternário e à fracturação, sendo posteriormente (re)adaptada à escala 1/25 000. Depois de georreferenciados e analisados relativamente à influência de alguns parâmetros condicionantes sobre o padrão da sua distribuição, os movimentos de vertente inventariados ajudaram a definir um quadro estrutural e morfodinâmico (fig. 5) caracterizados por fortíssimas correlações com a existência de socalços, pequenos canais com dinâmica flúvio-torrencial, declives com valores entre 24 e $32^{\circ}$ e exposição das vertentes para o quadrante oriental.

\section{Factores intrínsecos ao material rochoso (fracturação e lito-estratigrafia)}

No âmbito dos factores estruturais que julgámos serem importantes para ajudar a definir o quadro multivariado da distribuição espacial dos movimentos de vertente, procurámos destacar a importância da fracturação(7) e da lito-estratigrafia (quadro I).

(6) De acordo com este critério atribuímos pesos "1", "2" e " 3 " aos mapas intercalares efectuados, relativos ao zonamento da probabilidade de ocorrência de movimentos do tipo G1, G2 e G3, respectivamente.

(7) As diversas funcionalidades do ArcView GIS não permitem no entanto, cruzar informação de temas lineares com temas poligonais. Deste modo tivemos de transformar os temas lineares (hidrografia e fracturação) em temas poligonais criando para o efeito aquilo que a linguagem do sistema designa por buffer e que em termos gráficos se trađuz pela construção de 


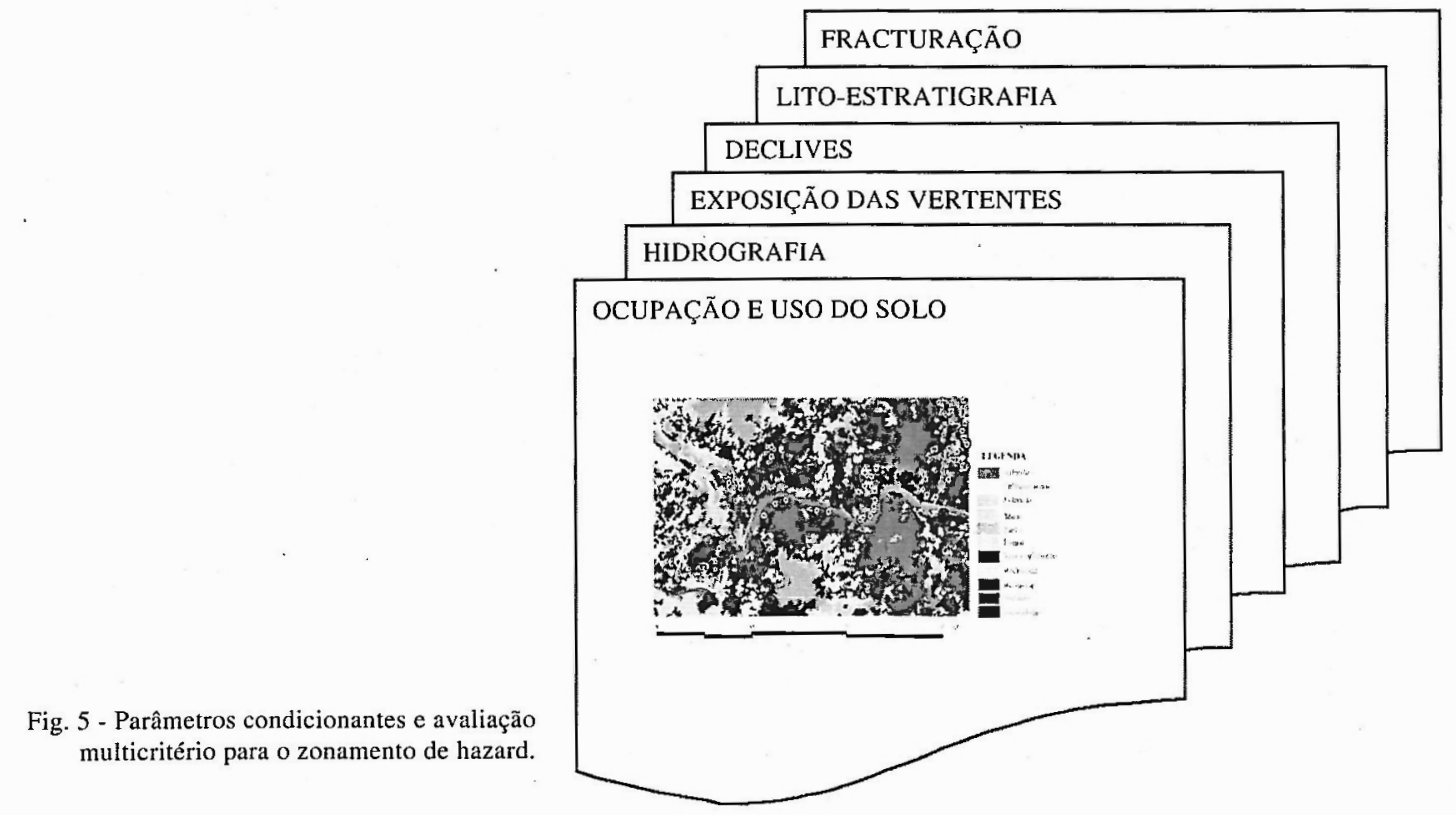

\begin{tabular}{|c|c|c|c|c|c|c|c|c|c|c|c|c|c|c|}
\hline \multicolumn{3}{|l|}{ FACTORES } & \multicolumn{12}{|c|}{ MOVIAIENTOS } \\
\hline \multicolumn{3}{|c|}{ CLASSES } & \multicolumn{3}{|c|}{ G1 } & \multicolumn{3}{|c|}{$\mathrm{C}_{2}$} & \multicolumn{3}{|c|}{ G3 } & \multicolumn{3}{|c|}{ TOTAL } \\
\hline & & AREA (fan') & $\pi$ & sl (\%h) & $x^{2}(\%)$ & $\pi$ & rl $(9 \%)$ & $r_{2}^{2}(\%)$ & $\mathbf{n}$ & Sl (\%) & $r 2(\%)$ & $\mathbf{n}$ & $\operatorname{Il}(\%)$ & $x^{2}(\%)$ \\
\hline \multicolumn{2}{|c|}{ BUFFERFRACTURAS } & 9,05 & 8 & 2,4 & 2 & 0 & o & 0 & 0 & 0 & 0 & 8 & 2,4 & 2 \\
\hline \multirow{12}{*}{ LTOLOCLA } & areis e caseforuviats & 1,06 & 0 & $\mathbf{0}$ & 0 & 0 & $\mathbf{0}$ & 0 & 0 & $\mathbf{0}$ & 0 & $\mathbf{0}$ & $\mathbf{0}$ & 0 \\
\hline & dep vertente & 0,13 & 0 & 0 & 0 & 0 & 0 & 0 & $\mathbf{0}$ & o & 0 & 0 & a & 0 \\
\hline & dep. fhuviais & $2,00^{\circ}$ & 0 & 0 & 0 & 0 & $\mathbf{0}$ & 0 & a & $\mathbf{0}$ & 0 & 0 & o & 0 \\
\hline & rochas sibir, Hhut ano & $\leq 29$ & o & 0 & 0 & 0 & $\mathbf{0}$ & $\mathbf{0}$ & a & 0 & 0 & 0 & 0 & 0 \\
\hline & rochas ordor.metam & 1,19 & 1 & 0,3 & 0,2 & 0 & 0 & $\mathbf{0}$ & $\mathbf{0}$ & 0 & 0 & 1 & 0 & 0,2 \\
\hline & quartaitos ord $\mathrm{d} / \mathrm{czz}$ & 7,76 & 8 & 2,4 & 1,8 & 2 & 3,4 & 0,5 & 1 & 5 & 0,2 & 11 & $\mathbf{0}$ & 3,5 \\
\hline & compl, xist.-grasy. & 99,07 & 282 & 83,4 & 63,9 & 76 & 91,6 & 17,2 & 17 & 85 & 3,9 & 375 & 0 & 85 \\
\hline & gravito atsalino & 11,17 & 4 & 1,2 & 0,9 & 0 & o & 0 & 2 & 10 & 0,5 & 6 & $\mathbf{0}$ & 1,4 \\
\hline & granito porfinöide & 28,75 & 41 & 12,1 & 9,3 & 4 & 4,8 & 0,9 & $\mathbf{0}$ & 0 & 0 & 45 & $\mathbf{0}$ & 10,2 \\
\hline & cutras rochis flon. & 1,02 & 2 & 0,6 & 0,5 & I & 1,2 & 0,2 & 0 & o & $\mathbf{0}$ & 3 & 0 & 0,7 \\
\hline & quatzo filonians & 0,12 & B & 0 & B & o & o & D & 0 & 0 & 0 & 0 & 0 & c \\
\hline & TOTAL & 157,62 & 338 & 100 & 76,6 & 83 & 100 & 18,8 & 20 & 100 & 4,6 & 441 & 0 & 100 \\
\hline
\end{tabular}

Quadro I - Distribuição dos movimentos de vertente em função da litologia e da fracturação

n- frequência absoluta dos movimentos de vertente; $\mathbf{r}(\%)$-frequência de movimentos de vertente relativamente ao total de cada tipologia; r2(\%)- frequência de movimentos de vertente relativamente ao total

No que diz respeito à fracturação (fig. 6) parece ser digno de registo apenas o sentido de reforço local de outros factores dado que, por si só, os resultados obtidos directamente relacionáveis com acidentes fracturantes mostram um reduzido grau de correlação entre este factor e a distribuição dos movimentos de vertente. Foram apenas registados 8 movimentos do tipo G1 ( $2,4 \%$ de r1), com influência perceptível de acidentes fracturantes.

As grandes linhas da litologia em confronto, são importantes pelo comportamentogeomecânico diferencial intrínseco aos vários tipos de rocha; a presença ou ausência de cobertura sedimentar com carácter de

polígonos cuja morfologia e dimensão areal dependem da morfologia da linha inicial e do valor numérico (neste caso $100 \mathrm{~m}$ ) considerado como área de influência da linha de água ou da fractura. Uma vez efectuada esta transformação, igualmente necessária para o cruzamento da informação alfanumérica dos diferentes temas em análise, o valor areal para tema poligonal assim definido evidenciou um valor de $9,05 \mathrm{~km}^{2}$ (cfr. quadro I). [jgs0] depósito detrítico ou de perfil de alteração com resíduo sólido in situ revelou constituir aspecto fundamental para a compreensão do contributo da litologia, concretamente da lito-estratigrafia, para a distribuição dos movimentos de vertente ${ }^{(8)}$. Se a natureza essencialmente xistosa do Complexo xisto-grauváquico (CXG) se pode correlacionar com perfis de alteração de natureza pelítica, caracterizados por uma fina mas densa e abundante matriz, geralmente argilosa, com forte capacidade de absorção e retenção de água e, por isso, muito impermeável, a textura silto-argilosa ganha expressão quando a proveniência denuncia as

(8) Devemos, no entanto, acrescentar que, tal como referimos em trabalho anterior (G. SANTOS, CUNHA E FERREIRA, em publicação) a história recente do Douro diz-nos que homens munidos de ferramentas e meios mais ou menos rudimentares recorreram também à força animal para colocar muitas toneladas de material detrítico que deram corpo e forma àquilo que hoje vemos e reconhecemos como "os socalcos do Douro". Está, por isso, bem presente a forte antropização da área, na morfologia mas também na própria cobertura detrítica das vertentes, designadamente quando estamos na presença de socalcos. 


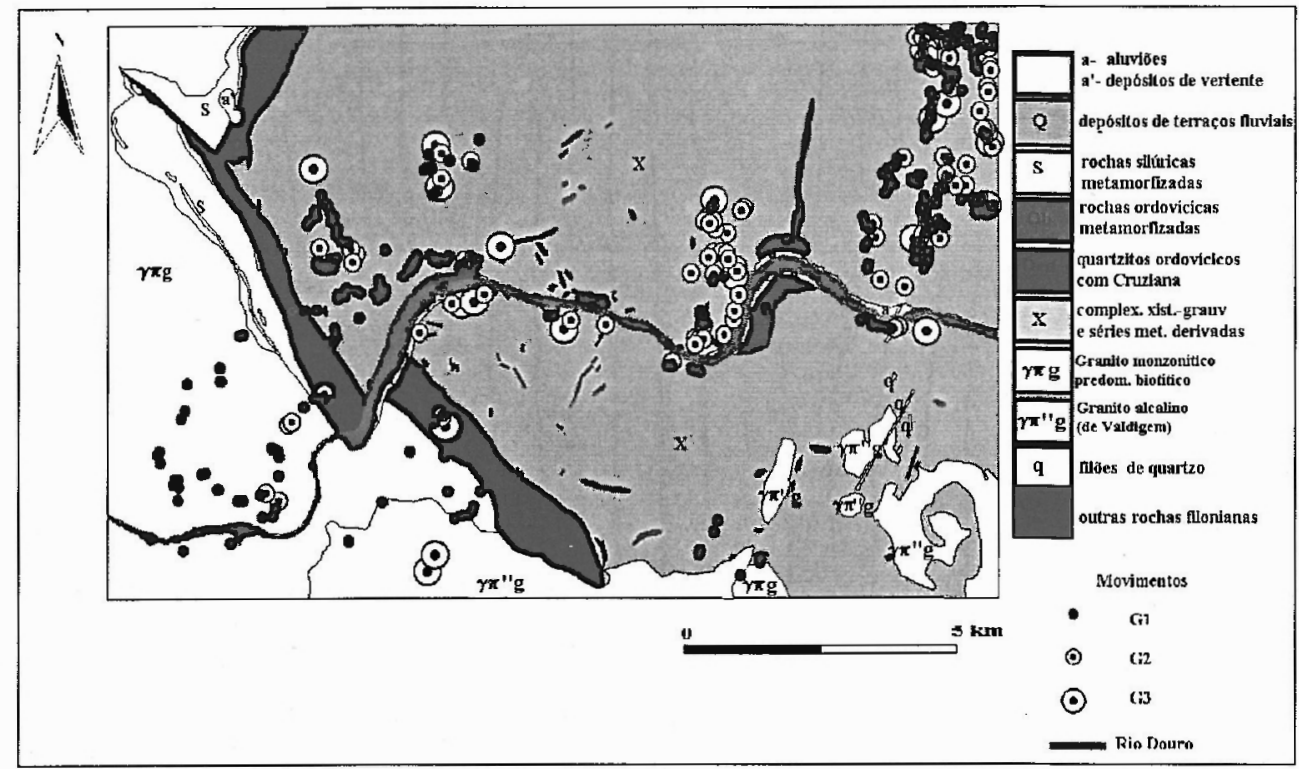

Fig. 6- Distribuição dos movimentos de vertente em função do tema Bufferfracturas. facies mais grauvacóides e quartzíticas do referido Complexo. Já a textura silto-arenosa surge quase sempre na dependência de mantos de alteração granítica ou de depósitos que neles encontram filiação. Entre a rocha coerente cuja permeabilidade está fortemente condicionada pela densidade da fracturação, e a base da cobertura detrítica, define-se uma descontinuidade que devido à acção da água funciona frequentemente como linha potenciadora de manifestações de instabilidade nas vertentes, ao longo da qual ocorrem, por exemplo, importantes deslizamentos, facto aliás, já destacado por REBELO (1981).

A grande maioria dos 441 movimentos de vertente registados (cfr. quadro I e fig. 7) ocorre sempre na dependência de um quadro lito-estratigráfico com as características járeferidas, salientando-se a importância da cobertura detrítica de matriz essencialmente argilosa ou argilo-siltosa, no contexto em que a litologia do (CXG)é dominante. Assim, destacamos os 282 registos de movimentos do tipo G1, 76 de G2 e 17 de G3 o que, por categoria dos movimentos, corresponde, respectivamente, a $83,4 \%$ dos movimentos $\mathrm{G} 1$ (r1), 91,5\% dos movimentos $\mathrm{G} 2$ (r1) e $85 \%$ dos movimentos G3 (r1). Sempre que uma cobertura detrítica com textura arenosa ou silto-arenosa, com espessura mínima da ordem dos 1,5 metros se sobrepõe ao granito monzonítico, porfiróide de grão médio a fino, predominantemente biotítico, a ocorrência de movimentos de vertente, principalmente do tipo G1 é também significativa destacando-se os 41 registos deste tipo o que corresponde a $12,1 \%$ do total. Foram também registados alguns movimentos de vertente em domínios líticos de maior coerência e resistência quer à alteração quer a processos de natureza mecânica, que garantiam pelo menos do pontode vista teórico, maior imunidade a este tipo de fenómenos; tal é, por exemplo, o caso dos 2 movimentos do tipo Gl e 1 do tipo G2 ocorridos sobre rochas filonianas, facto que só entendemos se pensarmos que estavam cobertas por um "depósito" argiloso relativamente espesso proveniente de áreas próximas de socalcos situados a montante, na litologia do CXG. De modo análogo, sobre quartzitos e outras rochas ordovícicas metamorfizadas, os 8 movimentos do tipo G1 e 2 do tipo G2 só podem ser explicados com recurso a um quadro litostratigráfico semelhante ao anterior. Os movimentos de grau 3, tal como na litologia do CXG, apenas têm 2 registos no granito alcalino de grão grosseiro a médio (granitode Valdigem) e 1 nos quartzitos ordovícicos com Cruziana; ocorrem na dependência de uma cobertura sedimentar arenosa, por vezes, areno-pelítica, mas não podemos deixar de relacionar estes movimentos com a importância de outros factores, designadamente, com a existência de pequenos canais ${ }^{(9)}$.

\section{Factores intrínsecos à vertente (declives e exposição das vertentes)}

Alguns parâmetros morfológicos intrínsecos à vertente ajudam igualmente a compreender o padrão

(9) Encontrámos muitas situaçŏes em que se encontram desviados do seu curso natural, ou, de modo mais frequente, obstruídos por construçōes; - por resíduos antrópicos ou mesmo por detritos transportados pèlas linhas de água em condições de um acréscimo coevo mas circunstancial de competência e capacidade de transporte, certamente decorrentes de episódios mais ou menos duradouros e repetidos de precipitação intensa. Este facto remete-nos para a ideia, já referida, de que os factores condicionantes da estabilidade das vertentes não são necessariamente independentes, dificultando assim o esforço de sistematização presente em qualquer análise de feição mais sectorial. 


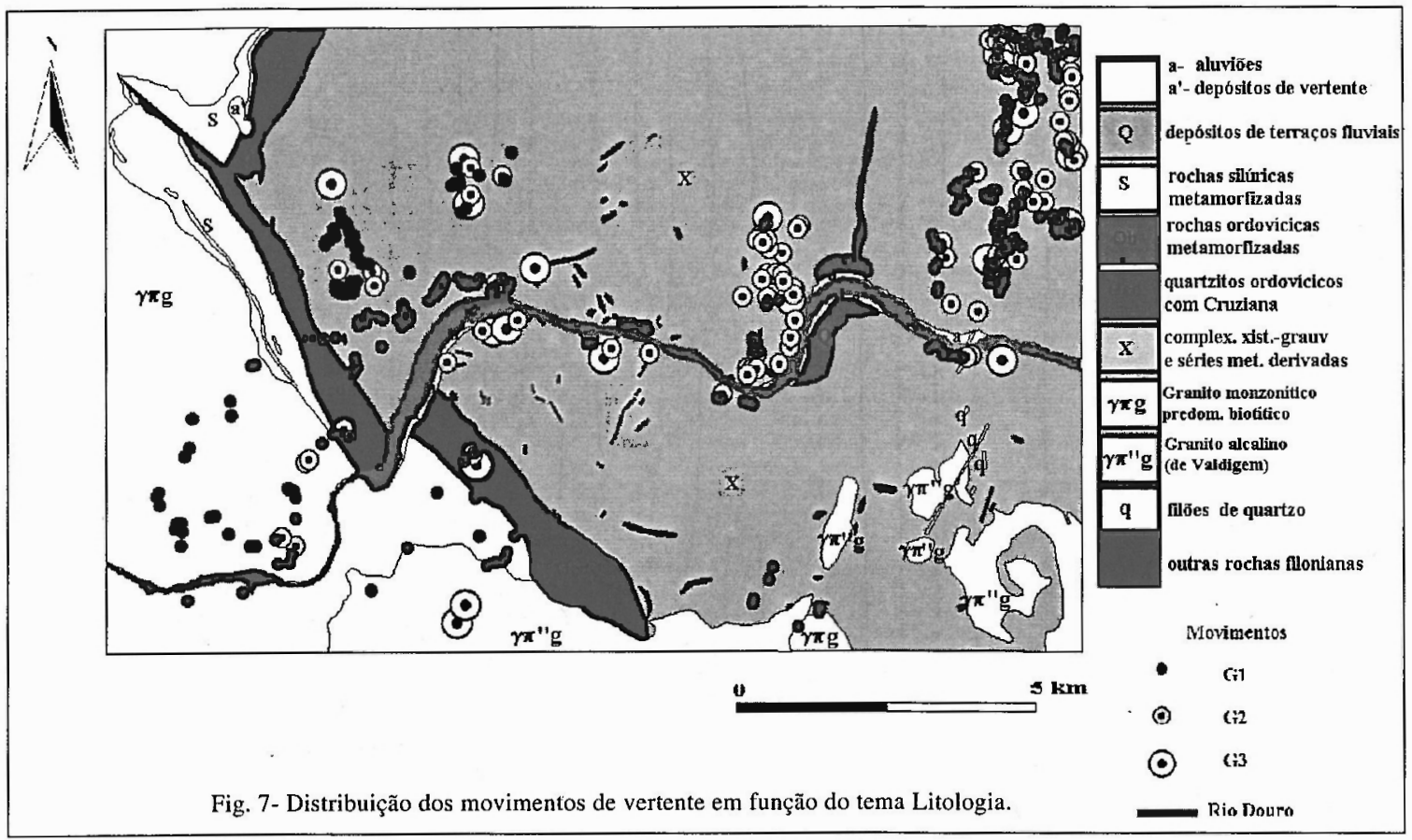

da distribuição dos movimentos de vertente. Factores morfológicos como o declive e o perfil da vertente são parâmetros geralmente aceites como factores condicionantes da estabilidade das vertentes, logo, da variabilidade da susceptibilidade a estes fenómenos. As maiores dificuldades em tratare representar graficamente os dados morfológicos relativos aos declives para uma área tão extensa, levou-nos a considerar os valores das inclinações das vertentes, geralmente aceites como um dos mais importantes factores com visível contribuição para a ocorrência de movimentos de vertente ${ }^{(10)}$. Na análise dos factores morfológicos considerámos ainda a importância da exposição das vertentes.

No que diz respeito aos declives, em termos de área ocupada (quadro II e fig. 8) destacamos os

(10) A forte componente antrópica das vertentes que se percebe (e já se referiu) ao nível da forma mas também da própria cobertura detrítica, ajuda a compreender a localização de alguns movimentos do tipo debris, earth ou mudflow e também de mecanismos complexos do tipo flow slide referidos por HUTCHINSON (1988) e IBSEN, BRUNSDEN, BROMHEAD \& COLLISON (1996) na obra de DIKAU ET AL. (1996) a que os autores dedicam o capítulo 8; por outro lado, este mesmo quadro favorece também a concentração da escorrência e consequente abertura de ravinamentos (REBELO, 2001) em favor de uma cobertura detrítica branda com fraco grau de coesão ede compacidade (que em função da rede de fracturação podem mesmo atingir o próprio soco) e de declives, por vezes, muito acentuados que nesta área podem atingir valores na ordem dos 64-72 $2^{\circ}$. Não sendo em vertentes com estes valores de declive que se registaram movimentos de vertente (cfr. quadro II) é muitas vezes nesta áreas que se localizam as cabeceiras de canais que acabam por propagar para jusante condições de instabilidade que se iniciam a montante e se evidenciam pela abertura de fendas de retracção e pela ocorrência, ou eminência de virem a ocorrer, de pequenos desabamentos e respectivos depósitos residuais.
$50,9 \mathrm{~km}^{2}$ onde as vertentes apresentam inclinações com valores compreendidos entre 16 e $24^{\circ}(32,4 \%$ da área total) e os $39,25 \mathrm{~km}^{2}$ com valores de $24-32^{\circ}$ $(24,96 \%$ da área total). São ainda de assinalar os $6,1 \mathrm{~km}^{2}$ de área ocupada por declives superiores a $48^{\circ}, 3,8 \%$ da área total, mas não deixam também de ser importantes, chegando mesmo a impressionar os $0,1 \mathrm{~km}^{2}$ de área onde existem declives compreendidos entre 64 e $72^{\circ}$.

Uma leitura imediata do quadro II permite-nos constatar, desde logo, a importância dos declives compreendidos entre os 16 e os $32^{\circ}$, destacando-se os 122 movimentos do tipo G1 (36,1\% de r1), 28 do tipo G2 (33,7\% de r1) e 11 do tipo G3 (55\% de r1). A acentuada inclinação de muitas das vertentes da área confere-lhes um significativo índice de susceptibilidade a esta tipologia de processos de evolução de vertentes, destacando-se a importância dos 6 movimentos do tipo G1, 2 do tipo G2 e 1 do tipo G3, o último dos quais com um fortíssimo poder de destruição mas que, apesar de tudo, não provocou vítimas mortais, devidoà reduzida vulnerabilidade dos espaços afectados pelo movimento, local de ocorrência e distribuição espacial.

Ao nível da exposição das vertentes (quadro III e fig. 9), assumem particular importância os 27,1 $\mathrm{km}^{2}$ de áreas que o sistema designa por "planas" ( $17,23 \%$ do total), áreas com exposição indiferenciada onde incluímos a superfície ocupada por leitos de cheia de linhas de água, topos aplanados de vertentes mas também os muitos sectores que caracterizam a 


\begin{tabular}{|c|c|c|c|c|c|c|c|c|c|c|c|c|c|c|}
\hline \multirow{3}{*}{ FACTORES } & & & \multicolumn{12}{|c|}{ MOVIMLETIOS } \\
\hline & \multicolumn{2}{|l|}{ CLASSES } & \multicolumn{3}{|c|}{ G1 } & \multicolumn{3}{|c|}{62} & \multicolumn{3}{|c|}{6} & \multicolumn{3}{|c|}{ TOTAL } \\
\hline & & AREA (kin') & $\mathbf{n}$ & Il (\%) & $r^{2}(96)$ & $\mathbf{n}$ & rl (\%) & $r_{2}^{2}(96)$ & $\pi$ & rl (\%) & $x 2(36)$ & $\Omega$ & rl (9) & $x^{2}(\%)$ \\
\hline \multirow{10}{*}{ DECLIVES } & $0 \div 8$ & 17,68 & 19 & 5,6 & 4,3 & 0 & 0 & 0 & 0 & 0 & 0 & 19 & 0 & 4,3 \\
\hline & 8 a 16 & 27,42 & 31 & 9,2 & 7 & 5 & 6 & 1,1 & 0 & 0 & 0 & 36 & 0 & 8,2 \\
\hline & $15 \div 24$ & 50,90 & 88 & 26 & 19,9 & 33 & 39,8 & 7,5 & 3 & 15 & 0,7 & 124 & 0 & 28,1 \\
\hline & 24 a 32 & 39,25 & 122 & 36,1 & 27,7 & 28 & 33,7 & 0,3 & 11 & 58 & 2,5 & 101 & 0 & 36,5 \\
\hline & $32 \approx 40$ & 16,34 & 44 & 13 & 10 & 10 & 12,1 & 2,3 & 3 & 15 & 0,7 & 57 & 0 & 12,9 \\
\hline & $40 \times 48$ & 4,00 & 28 & 8,3 & 6,3 & 5 & 6 & 1,1 & 2 & 10 & 0,5 & 35 & 0 & 7,9 \\
\hline & 48 a 56 & 1,45 & 6 & 1,8 & 1,4 & 2 & 2,4 & 0,5 & $\mathbf{I}$ & 5 & 0,2 & 9 & 0 & 2,1 \\
\hline & 56 a 64 & 0,22 & o & 0 & 0 & 0 & o & 0 & o & 0 & 0 & o & 0 & B \\
\hline & 64 a 72 & 0,00 & 0 & 0 & 0 & 0 & 0 & 0 & 0 & 0 & 0 & o & 0 & 0 \\
\hline & TOTAL & 157,25 & 338 & 100 & 76,6 & 83 & 100 & 18,8 & 30 & 100 & 4,6 & 441 & 0 & 100 \\
\hline
\end{tabular}

Quadro II - Distribuição dos movimentos de vertente por classes de declive

n- frequência absoluta dos movimentos de vertente; rl 1 \%)-frequência de movimentos de vertente relativamente ao total de cada tipologia; r2(\%)- frequência de movimentos de vertente relativamente ao total

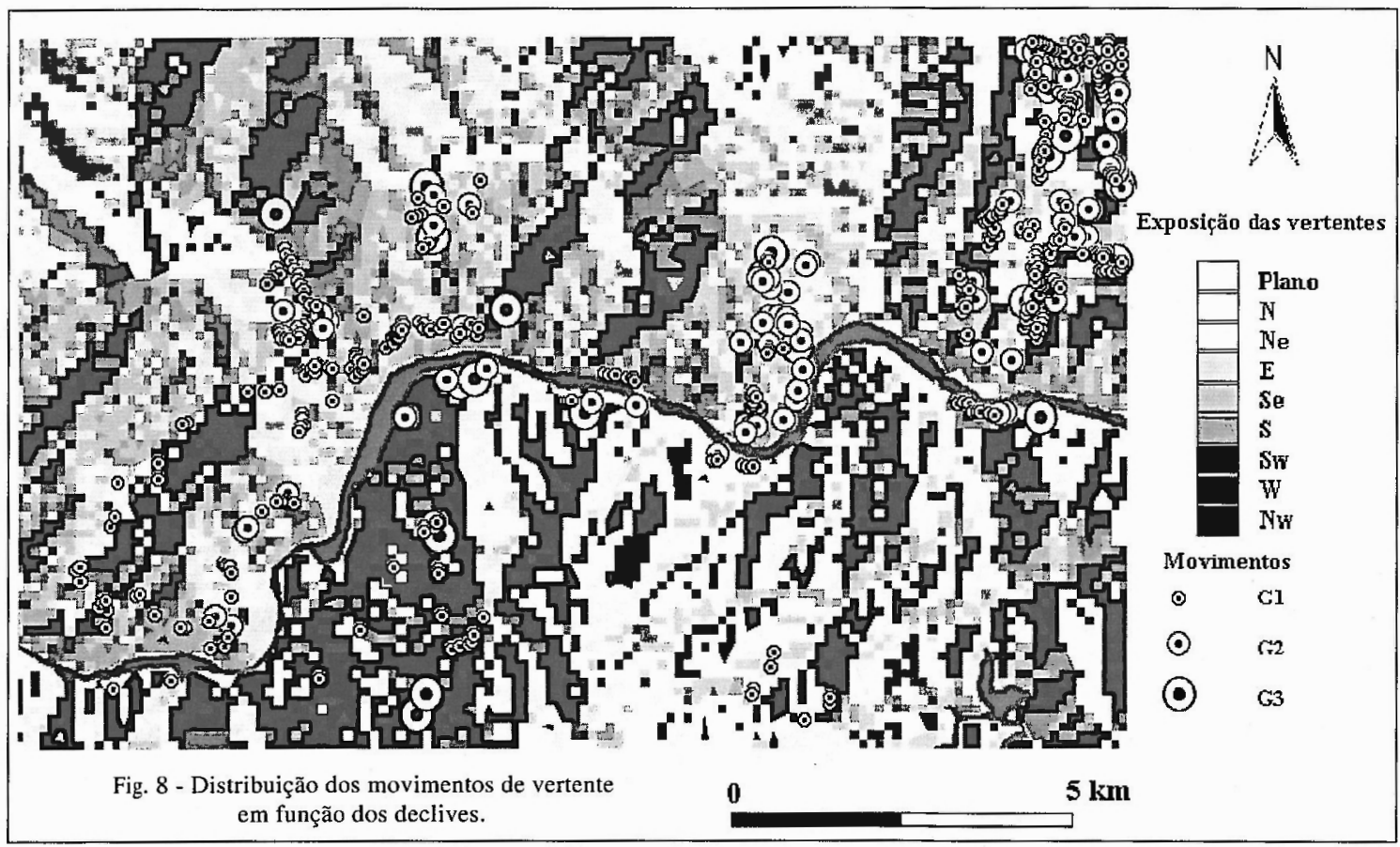

maioria dos socalcos construídos para implantação da vinha e da oliveira. A distribuição dos movimentos por classes de exposição das vertentes, apesar de menos heterogénea do que no caso dos declives, não deixa também de realçar o importante significado das exposições Ee NEonde, no seu conjunto, ocorreram
107 movimentos do tipo G1 (31,7\% de rl), 26 do tipo G2 (31,3\% de r1) e 8 do tipo G3 (40\% de r1). Finalmente não podemos deixar de assinalar ainda os 50 registos de movimentos do tipo G1 em áreas com exposição indiferenciada, com localização nos sectores planos dos socalcos.

\begin{tabular}{|c|c|c|c|c|c|c|c|c|c|c|c|c|c|c|c|}
\hline \multicolumn{4}{|l|}{ FACTORES } & \multicolumn{12}{|c|}{ MOVIMENTOS } \\
\hline \multirow{2}{*}{\multicolumn{4}{|c|}{ CLASSES }} & \multicolumn{3}{|c|}{ G1 } & \multicolumn{3}{|c|}{$\mathrm{G} 2$} & \multicolumn{3}{|c|}{ C3 } & \multicolumn{3}{|c|}{ TOTAL } \\
\hline & & & AREA $\left(\mathrm{km}^{\prime}\right)$ & n & $r 1(\%)$ & $r^{2}(\%)$ & $n$ & $r \mathrm{i}(\%)$ & $r^{2}(\%)$ & $\mathrm{n}$ & $r l(\%)$ & $r(\%)$ & $\mathbf{n}$ & rl (\%) & $r(\%)$ \\
\hline \multirow{10}{*}{ EXPOSIÇŌES } & Plano & & 27,10 & 50 & 14,8 & 11,3 & 12 & 14,5 & 2,7 & 2 & 10 & 0,4 & 64 & o & 14,4 \\
\hline & $N$ & & 13,87 & 33 & 6,8 & 5,2 & 7 & 8,5 & 1,6 & 1 & 5 & 0,2 & 31 & o & 7 \\
\hline & $\mathrm{Ne}$ & & 19,08 & 49 & 14,5 & 11,1 & 12 & 14,5 & 2,7 & 5 & 25 & 1,1 & 66 & 0 & 15 \\
\hline & $\mathbf{E}$ & & 18,61 & 58 & 17,2 & 15,1 & 14 & 16,9 & 3,3 & 3 & 15 & $v, 7$ & 75 & v & 17 \\
\hline & $\mathrm{Se}$ & & 15,38 & 39 & 11,5 & 8,8 & 9 & 10,8 & 2 & 0 & o & 0 & 48 & 0 & 10,9 \\
\hline & Se & & 12,97 & 36 & 10,7 & 8,2 & 5 & 6 & 1,1 & 2 & 10 & 0,5 & 43 & 0 & 9,8 \\
\hline & Sw & & 18,12 & 32 & 9,4 & 7,3 & 9 & 10,8 & 2 & 3 & 15 & 0,7 & 44 & 0 & 10 \\
\hline & $\mathrm{w}$ & & 16,87 & 22 & 6,5 & 5 & 9 & 10,8 & 2 & 2 & 10 & 0,5 & 33 & o & 7,5 \\
\hline & $N w$ & & 15,30 & 29 & 8,6 & 6,6 & 6 & 7,2 & 1,4 & 2 & 10 & 0,5 & 37 & 0 & 8,4 \\
\hline & $A L$ & & 157,28 & 338 & 100 & 76,6 & 83 & 100 & 18,8 & 20 & 100 & 4,6 & 441 & B & 100 \\
\hline
\end{tabular}

Quadro III- Distribuição dos movimentos de vertente em função da de exposição das vertentes

$\mathrm{n}$ - frequência absoluta dos movimentos de vertente; $\mathrm{rl}(\%)$ - frequência de movimentos de vertente relativamente ao total de cada tipologia; r2(\%) - frequência de movimentos de vertente relativamente ao total 


\section{Hidrografia}

$\mathrm{Na}$ categoria de factores condicionantes da estabilidade das vertentes optámos por considerar a importância das linhas de água e da ocupação e uso do solo.

Apesar de se tratar de um tema de linhas, criando uma situação semelhante ao que se havia já passado quando abordámos a importância da fracturação, optámos por utilizar também os dados relativos à hidrografia (quadro IV e fig. 9), porque estávamos convictos, desde o início, de que a grande maioria dos 441 movimentos de vertente registados, e a tipologia G3, em particular, pareciam surgir com um elevado grau de associação a traçados de linhas de água, normalmente inactivas e que em alguns dos casos nem sequer encontram representação cartográfica à escala inicialmente utilizada, 1/25000. Assim, criou-se um tema poligonal que permitisse ao sistema cruzar informação alfanumérica entre os diferentes temas, obedecendo aos mesmos critérios utilizados no tema da fracturação, ou seja, a partir do talvegue da linha de água considerou-se uma área de 100 metros ( $50 \mathrm{~m}$ para cada um dos lados) com influência mais ou menos directa do traçado fluvial. Esta meto- dologia definiu, assim, um espaço físico com uma superfície de $50,4 \mathrm{~km}^{2}$ aproximadamente (quadro IV). A distribuição dos movimentos de vertente relativamente ao traçado das linhas de água que surge, assim, em função da extrapolação, e cujo erro de leitura ao nível da associação entre as variáveis não nos parece significativo, permite constatar uma associação evidente, como se admitia desde o início, entre a distribuição dos movimentos de vertente do tipo G3 e a localização de pequenos canais; dos 20 registos de movimentos do tipo $\mathrm{G} 3,11$ (55\% de $\mathrm{r} 1$ ) ocorreram neste quadro morfo e hidrodinâmico. As duas restantes tipologias de movimentos G2 e G1 surgem 24 e 70 vezes, $(28,9 \%$ de r 1$)$ e $(20,7 \%$ de r1), respectivamente, associadas a um quadro com características semelhantes, não sendonegligenciável, também aqui, a importância deste factor.

\section{Biogeografia (ocupação e uso do solo)}

Outro dos factores que considerámos importante para a investigação em curso foi a ocupação e uso do solo. A estabilidade de uma vertente depende, entre outros factores, da existência ou ausência de vegetação;

\begin{tabular}{|c|c|c|c|c|c|c|c|c|c|c|c|c|c|}
\hline FACTORES & & & & & & & VDREN & & & & & & \\
\hline & & & $\mathrm{Cl}$ & & & 62 & & & 63 & & & TOTAL & \\
\hline & $\operatorname{AKEA}\left(\mathrm{km}^{2}\right)$ & $\mathbf{n}$ & IL(\$6) & $r^{2}(150)$ & $\mathbf{n}$ & TI (50) & $r 2(\%)$ & $n$ & $r \mid(\%)$ & $12\left(w_{1}\right)$ & $\mathbf{n}$ & $\mathrm{r} 1(\%)$ & $x^{2}\left(y_{0}\right)$ \\
\hline BUFFERTALVEGUES & 50,42 & 70 & 21 & 16 & 24 & 29 & 7 & 11 & 55 & 3 & 105 & 100 & 36 \\
\hline
\end{tabular}

Quadro IV - Distribuição dos movimentos de vertente em função do tema hidrografia

n -frequência absoluta dos movimentos de vertente; rl(\%) - frequência de movimentos de vertente relativamente ao total de cada tipologia; r $2(\%)$ - frequência de movimentos de vertente relativamente ao total

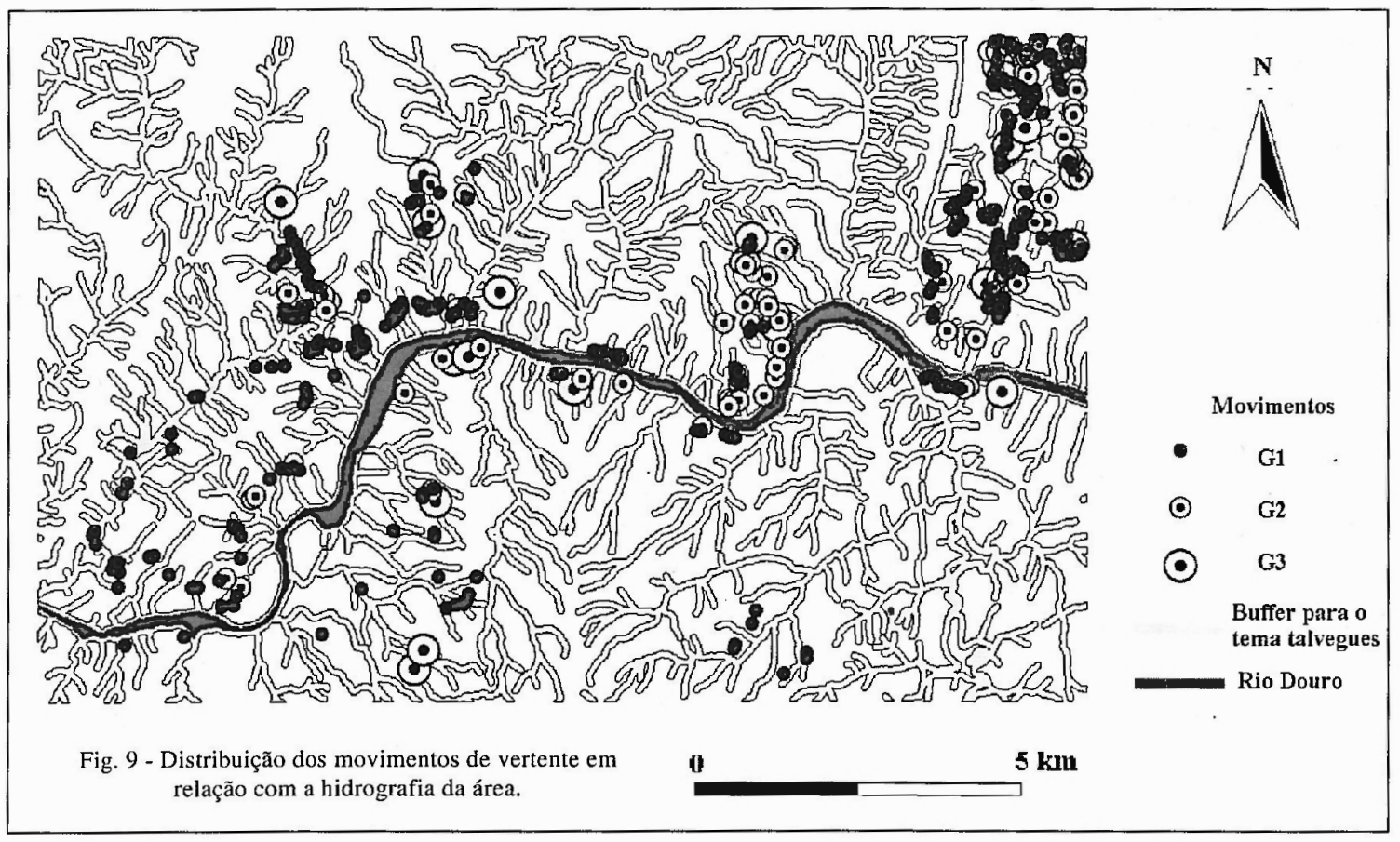


quando existe, o tipo de formação vegetal é um subfactor a ter em conta quando se analisam as causas de manifestações de instabilidade como a ocorrência de movimentos de vertente. Uma vertente com ocupação arbustiva, num dado momento, tem um determinado comportamento geomecânico em função de um quantitati vo de precipitação intensa e/ou acumulada durante vários dias ou mesmo meses; esse comportamento seria certamente diferente se a mesma vertente tivesse uma ocupação arbórea, por exemplo, de resinosas e respectivo cortejo florístico, ou uma ocupação herbácea propícia, por exemplo, para pasto. As consequências ecológicas decorrentes dos incêndios florestais ajudam a evidenciar a importância deste comportamento diferencial intrínseco a cada vertente, vamos ainda mais longe ao defender que é intrínseco mesmo a cada sector de uma vertente ${ }^{(11)}$ tal a diversidade de

(11) Note-se que falamos na mesma vertente em situações distintas e não em duas vertentes distintas! combinações de parâmetros geomecânicos que podem caracterizar os diferentes sectores. Tal como as suas propriedades geotécnicas, também os estados tensodeformacionais dos diversos sectores de uma vertente variam em função de factores como a própria densidade e dimensão da fracturação, diaclasamento, estratificação, entre outras linhas de descontinuidade intrínsecas ao material rochoso.

$\mathrm{A}$ análise do quadro $\mathrm{V}$ e a leitura da figura 10 permitem-nos realçar, desde logo, a vasta área ocupada pelos socalcos $\left(79,1 \mathrm{~km}^{2}-50,2 \%\right.$ da área total), que em termos de ocupação vegetal correspondem quase sempre a áreas de vinha ou olival. Salientamos ainda a fraca expressão de área de rocha nua, apenas $0,1 \mathrm{~km}^{2}$ que, de algum modo, permitem concluir sobre a importância da cobertura detrítica na área considerada. No que diz respeito ao padrão de distribuição dos movimentos de vertente, não podemos deixar de sublinhar a elevada concentração no espaçoidentificado

\begin{tabular}{|c|c|c|c|c|c|c|c|c|c|c|c|c|c|c|}
\hline \multicolumn{3}{|l|}{ FACTORES } & \multicolumn{12}{|c|}{ MOVDAFITIOS } \\
\hline \multicolumn{3}{|c|}{ CLASSES } & \multicolumn{3}{|c|}{ Cl } & \multicolumn{3}{|c|}{$C_{2}$} & \multicolumn{3}{|c|}{63} & \multicolumn{3}{|c|}{ TOTAL } \\
\hline & & AREA $\left(\mathrm{hm}^{-}\right)$ & $\mathbf{n}$ & rl (\%) & $x^{2}(90)$ & $\mathbf{n}$ & $r 1(96)$ & $I_{2}^{2}(\%)$ & $\mathrm{n}$ & s! $(9)$ & $x_{2}^{2}(36)$ & $\mathbf{n}$ & sl (9i) & $r(\%)$ \\
\hline \multirow{12}{*}{ OUSOLO } & Antustivo & 15,77 & 9 & 2,7 & 2 & 1 & 1,2 & 0,2 & 1 & 5 & 0,2 & 11 & 0 & 2,5 \\
\hline & Cult. Aravais & 7,70 & 4 & 1,2 & 0,9 & 1 & 1,2 & 0,2 & 0 & a & 0 & 5 & a & 1,1 \\
\hline & Follosas & 7,78 & 10 & 3 & 2,3 & 2 & 2,5 & 0,5 & 1 & 5 & 0,2 & 13 & 0 & 3 \\
\hline & Misto (follh + res.) & 10,54 & 11 & 3,2 & 2,5 & 1 & 1,2 & 0,2 & 0 & o & 0 & 12 & o & 2,7 \\
\hline & Pasto & 6,32 & 16 & 4,7 & 3,6 & 3 & 3,6 & 0,7 & 0 & 0 & 0 & 19 & 0 & 4,3 \\
\hline & Ponux & 6,78 & 21 & 6,2 & 4,8 & $\mathbf{I}$ & 1,2 & 0,2 & 0 & o & 0 & 22 & a & 5 \\
\hline & Fios a atboufeizas & 4,09 & 0 & 0 & 0 & 0 & 0 & 0 & 0 & 0 & 0 & 0 & 0 & o \\
\hline & Rocha-rnea & 0,00 & 0 & 0 & $B$ & $\mathbf{0}$ & 0 & 0 & 0 & o & 0 & 0 & 0 & 0 \\
\hline & Resinosas & 13,43 & 9 & 2,7 & 2 & 1 & 1,2 & 0,2 & 3 & 15 & 0,7 & 13 & 0 & 2,9 \\
\hline & Socalcos & 79,15 & 247 & 73 & 56 & 67 & 80,7 & 15,2 & 15 & 75 & 3,5 & 329 & 0 & 74,6 \\
\hline & Areas urbanas & 6,87 & 11 & 3,3 & 2,5 & 6 & 7,2 & 1,4 & 0 & a & D & 17 & 0 & 3,9 \\
\hline & TOTAL & 158,43 & 338 & 100 & 76,6 & 83 & 100 & 18,8 & 20 & 100 & 4,6 & 441 & 0 & IDn \\
\hline
\end{tabular}

Quadro V - Distribuição dos movimentos de vertente por classes de ocupação e uso do solo

$\mathrm{n}$ - frequência absoluta dos movimentos de vertente; $\mathrm{rl}(\%)$ - frequência de movimentos de vertente relativamente ao total de cada tipologia; r2(\%) - frequência de movimentos de vertente relativamente ao total

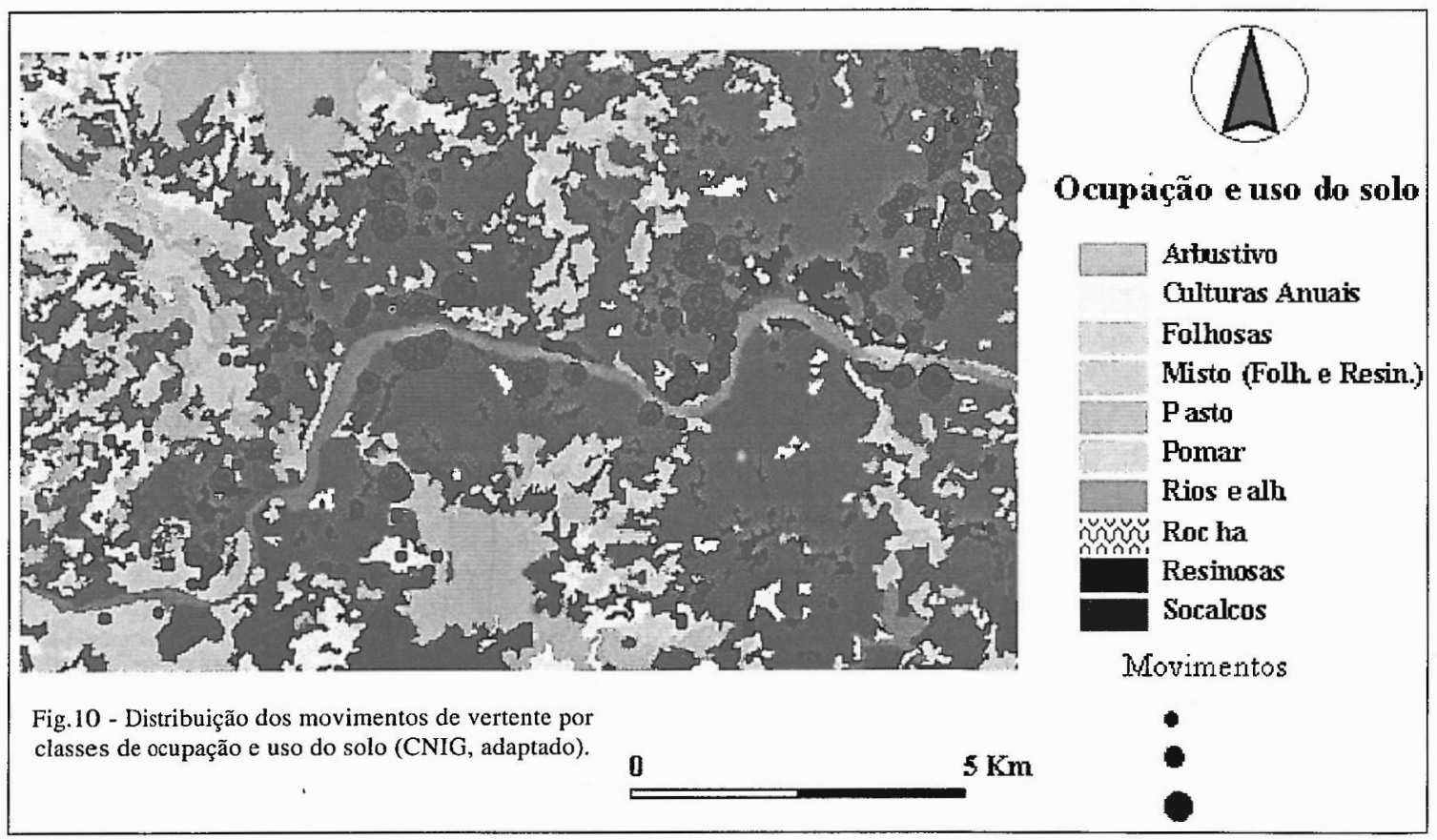


como área de socalcos sugerindo uma clara correlação entre as duas variáveis traduzida pela maior susceptibilidade destas vertentes a manifestações deste tipo de instabilidade; foram 247 os registos de movimentos do tipo G1 (73\% de r1), 67 do tipo G2 (80,7\% de r1) e 15 do tipo G3 (75\% de r1). A morfodinâmica das áreas de socalco, com cobertura detrítica de textura argilosa a silto-argilosa, caracteriza-se por um funcionamento com efeito de "toalha de absorção e infiltração das águas pluviais" locais mas também das que por escoamento subterrâneo ou por escorrência vêm de montante; ambas contribuem para a saturação de determinados sectores dos socalcos onde tantas vezes encontrámos sinais de instabilidade denunciada pelos pequenos movimentos que aí se desenvolveram, geralmente pequenos desabamentos mas também por movimentos complexos que evoluíram segundo um efeito que designamos por "dominó" que se caracterizam por uma distribuição em avanço e estilo sucessivo. Alguns destes movimentos de vertente destruíram, de modo irremediável, extensas áreas de vinha ou de olival. São também de assinalar os 6 movimentos do tipo $\mathrm{G} 2(7,2 \%$ de $\mathrm{r} 1)$ registados em áreas classificadas como áreas urbanas, na medida em que a sua dimensão longitudinal decamétrica coloca com frequência grandes problemas, na medida em que, de um modo geral, as vulnerabilidades aumentam significativamente em espaços urbanos.

\section{Factores desencadeantes (actividade antrópica, condições climáticas e meteorológicas)}

São vários os factores externos à vertente e/ou ao material rochoso que podem funcionar como estímulo, desencadeando ou catalisando processos de instabilidade nas vertentes. Do vasto leque de factores físicos destacamos a importância da precipitação (efeito intensidade e acumulação) cuja acção durante o Outono-Inverno 2000-2001 deverá ter sido determinante para o desencadear de manifestações de instabilidade nas vertentes da área em estudo. A intensidade e velocidade do trabalho de sapa fluvial e outros factores (embora sem grande significado na área em estudo) podem também contribuir para desencadear processos que culminam na instabilidade das vertentes.

Mas também as actividades humanas, desencadeiam, catalisam ou aceleram os processos de instabilidade nas vertentes. Entre as actividades frequentemente mais associadas com estas situações encontram-se a colocação de cargas estáticas e escavações, deflorestação, irrigação, flutuações súbitas e sensíveis em reservatórios hídricos (por exemplo barragens) com reflexo nos níveis freáticos e na piezometria, e alterações ou abandono de práticas agrícolas; todos estes factores, interactuantes, implicam mudanças sensíveis no funcio- namento morfodinâmico e no comportamento geomecânico das vertentes.

\section{Actividades antrópicas}

A integração das características do suporte físico com a dinâmica das sociedades humanas tem vindo a solicitar, cada vez mais, análises com carácter sistémico. Nos estudos de Geografia, esta sensibilidade, que foi já notada por CUNHA \& ROCHA (1997), reforça a necessidade de interligação do conhecimento geográfico (físico e humano) na análise e tentativa de explicação de fenómenos com causas e dinâmicas cada vez menos exclusivamente naturais.

$\mathrm{Na}$ área emestudo, as diversas actividades humanas, cumulativas e interactuantes com o conjunto dos restantes factores (condicionantes e desencadeantes) contribuem, por vezes de modo determinante, para a génese de condições de instabilidade nas vertentes. Na última década temos vindo assistir a uma crescente dinâmica, territorial em geral, e urbana em particular. Na tentativa de explicar a crescente procura de novos espaços nas vertentes (fig. 11) uma das razões mais invocadas pelas populações locais é o sentimento de segurança que aí encontrariam, concretamente no que diz respeito às cheias do Douro. Por outro lado, o incremento do turismo em espaço rural e de montanha tem-se reflectido na maior pressão sobre o território que começa por se fazer notar, desde logo, ao nível da demografia e-dos efeitos estranguladores dos espaços e das dinâmicas mas que se faz sentir também ao nível do aumento de fluxos e nas alterações impostas à paisagem. Estas alterações, para além de se traduzirem por um significativo aumento da percentagem de superfície construída, por outro lado, obrigam ao desvio de linhas de água ou à sua interrupção criando tensões hídricas que, numa primeira fase propagam para montante as condições de instabilidade, mas que numa fase subsequenteà ruptura dos equilíbrios no local onde se exerce o efeito de barragem, podem conduzir toda a vertente à sua movimentação. De referir ainda que a canalização das linhas de água em condutas claramente sub-dimensionadas (fig.12A) e concebidas para dar vazão a caudais médios, é um factor geralmente associado a rupturas e abatimentos de estradas (fig.12B). A aplicação de cargas estáticas (aterros) e a abertura de cicatrizes nas vertentes (desaterros) para construção estão também na origem de importantes alterações morfodinâmicas com influência significativa ao nível do bal anço estabilidade/instabilidade de vertentes. Finalmente, entre os diversos exemplos de actividades humanas que directa ou indirectamente contribuem para a instabilização das vertentes destacamos também a acção de impermebilização dos solos, que em muitos casos está na 
origem de condições potenciais de distúrbio, entendido na perspectiva de TOY \& HADLEY, referidos por TAVARES (2001).

\section{Condições climáticas e meteorológicas (período seco e precipitação)}

Um estudo sobre movimentos de vertente deve também dedicar máxima atenção ao quadro meteorológico. Se a cartografia pode ajudar a encontrar soluções para a componente espacial da previsibilidade, o conhecimento concreto dos processos que estiveram na origem dos movimentos, a sua parametrização morfodinâmica e, quando os dados disponíveis o permitirem, a análise de períodos de retorno de séries pluviosas, poderão contribuir para afinar tarefas de predição no tempo e optimizar a confiança das populaçổes no que diz respeito ao cálculo de factores de segurança. A maior parte dos movimentos de vertente analisados ocorreu no ano hidrológico 2000 -2001 em favor de um contexto meteorológico que se caracterizou por um período seco bastante longo após o qual ocorreram valores muito elevados de precipitação cuja importância se terá traduzido talvez mais pelo seu efeito acumulado.

Noque diz respeito às características da precipitação registada na Estação de Avisos do Douro (EAD) Régua $^{(12)}$ foi analisada a série de 11 anos (Janeiro 1990 - Janeiro 2001) tendo sido utilizados, para comparação, os dados oficiais da Estação Meteorológica

(12) Foran utilizados os dados reiativos à Estação de Avisos do Douro Régua ( $70 \mathrm{~m}$ de altitude) com valores disponíveis apenas para o período 1990-2000. Apesar de se contabilizarem já dados relativos a um período de $I 1$ anos, optámos por recorrer também à informação da estação meteorológica de Vila Real ( $560 \mathrm{~m}$ de altitude), de modo a obter dados para um intervalo de tempo mais alargado, concretamente o período 1961-90, mas também para efeitos de comparação com os dados da Régua.

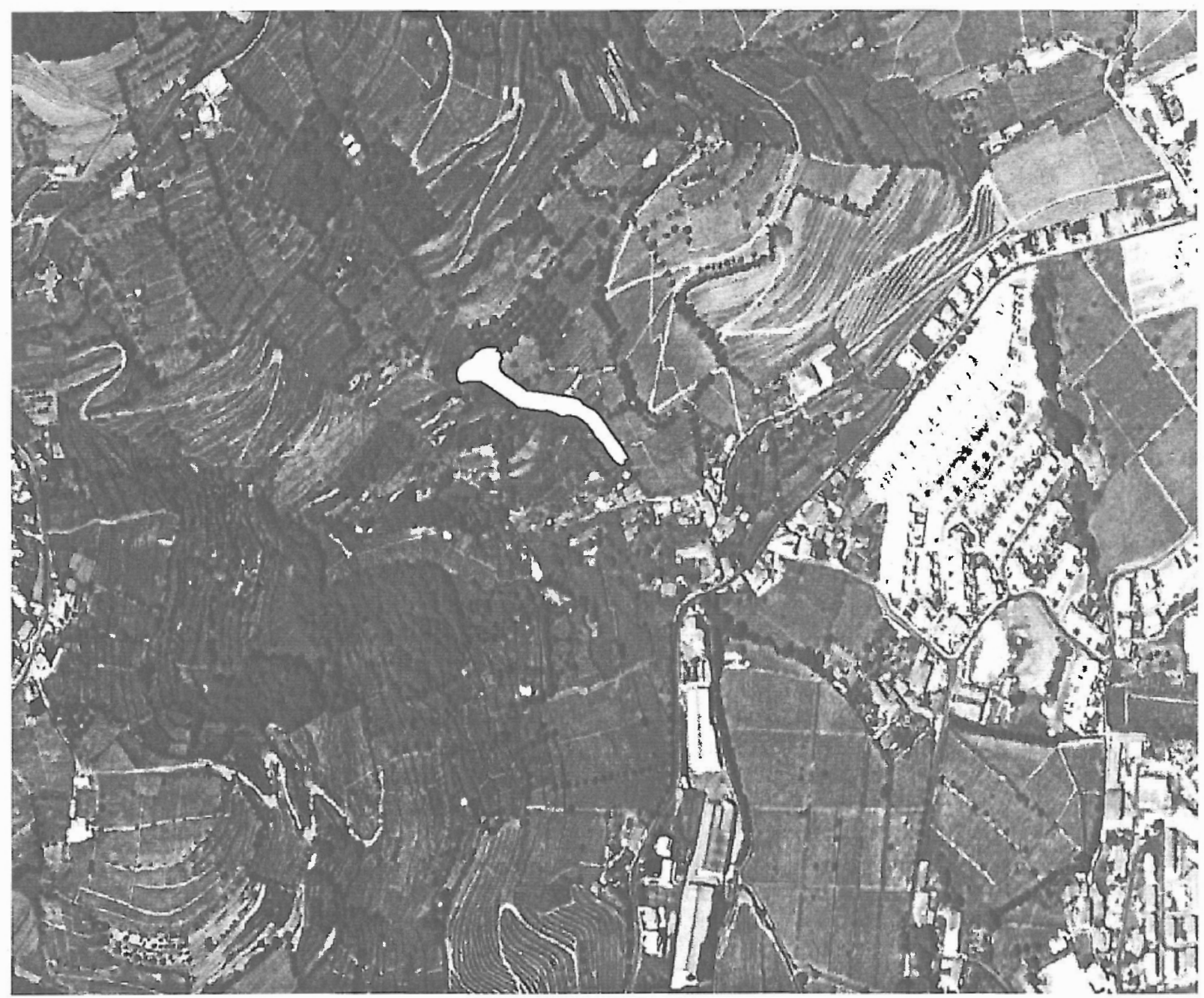

Fig. 11 - Localização do movimento complexo de Ariz-Godim (Régua) numa área de expansão urbana recente. Utilização parcial do ortofoto 1098 (CNIG). 


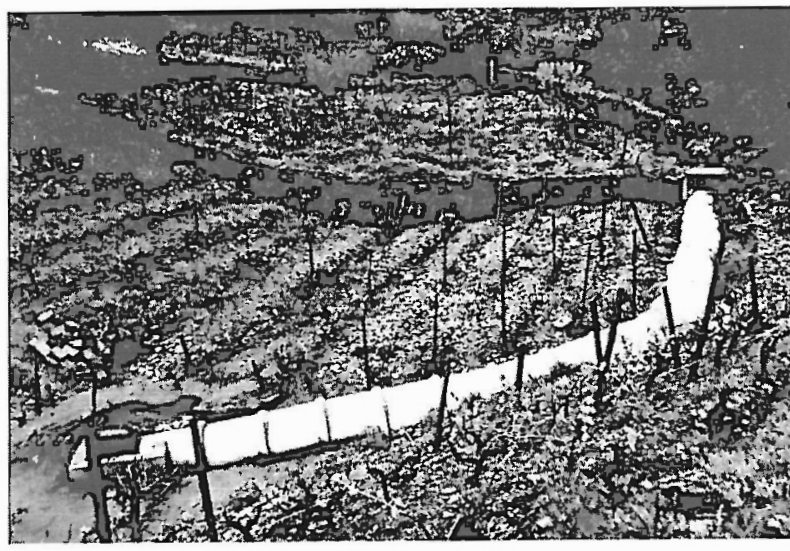

Fig. 12 - A - Exemplo de condutas sub-dimensionadas que drenam a vertente ocidental da estrada 313-1 que liga Vila Real e Peso da Régua; B - Deslizamento rotacional e fluxo de detritos na mesma estrada cerca de $100 \mathrm{~m}$ afastada da imagem anterior, em direcção à Régua.

de Vila Real relativos a um intervalo de tempo mais alargado (1961-1990). Foram ainda analisadas as séries de dias de precipitação registada nos quatro meses ${ }^{(13)}$ que antecederam os movimentos catastróficos de Ariz-Régua e de Alvações do Corgo-Sta. Marta de Penaguião (26 de Janeiro de 2001) e, finalmente, a série pluviosa que imediatamente antecedeu os referidos movimentos para se aferir o efeito da intensidade de precipitação. Ocorrendo após a existência de um longo período seco com duração muito superior aos 45 dias referidos como limiar mínimo ${ }^{(14)}$ para produzir alterações sensíveis nos níveis freáticos MÉNEROUD (1983), este contexto meteorológico deverá ter preparado o material para a movimentação.

Os valores normais para os respectivos períodos considerados mostram que, na Régua (fig. 13), o valor médio da precipitação anual foi de $851,2 \mathrm{~mm}$, enquanto que, em Vila Real o valor registado foi de $1111,5 \mathrm{~mm}$ (fig. 14). Verifica-se que os registos relativos ao Inverno de 2000-2001 relativos aos 4 meses antecédentes $(860,1 \mathrm{~mm}$ na Régua e $1059 \mathrm{~mm}$ em Vila Real), representam quase o dobro do normal para os períodos considerados $(493,4 \mathrm{~mm}$ e 552,9 $\mathrm{mm}$ respectivamente, figs.14 e 15) e que nestes quatro meses, em ambas as estações, o valor da precipitação ultrapassou o total médio anual para os - respectivos intervalos de tempo considerados.

(13) Referidos por GARLAND \& OLIVIER (1993), EYLES ET AL. (1978) eCROZIER (1986) utilizam os valores de precipitação anual e acumulada nos últimos 4 meses que antecederam o evento para a definição dos valores limiar a partir dos quais aumentariam as probabilidades de ocorrência de movimentos de vertente. Na obra de EYLES ET AL. (1978) são definidos limiares que os autores designaram por Maximum probabilily threshold ( $\mathrm{PTX})$ e Minimum probability (PTn), anuais e a 4 meses, a partir dos quais e, apenas para a área estudada pelos autores, haveria grande probabilidade de ocorrência de movimentos de vertente.

(14) Na Estação de Avisos do Douro na Régua, entre 23 de Maio e 30 de Outubro, verificaram-se 146 dias sem qualquer registo de precipitação, mas foram 158 se contabilizarmos os dias com valores inferiores ou iguais a $5 \mathrm{~mm}$ diários. Na estação meteorológica de Vila Real, a estação oficial da rede meteorológica nacional, mais próxima da área em estudo. entre 12 de Maio e 30 de Outubro houve 150 dias sem qualquer registo de precipitação e em 160 os valores foram inferiores ou iguais a $5 \mathrm{~mm}$ diários.

A (prudente) aplicação dos limiares ${ }^{(15)}$ propostos por EYLES ET AL. (1978), na obra citada, sublinha a importância da precipitação acumulada ao longo dos quatro meses que antecederam os movimentos (fig. 16). A importância dos valores acumulados nos quatro meses antecedentes leva-nos inclusivamente a pensar que, na área em estudo e atendendo aos registos históricos dos últimos 11 anos e ao quadro morfo-estrutural anteriormente apresentado, sempre que na sequência de um período seco suficientemente longo, os valores acumulados de precipitação se aproximem de $100 \%$ do total anual médio, se deverá atingir um contexto crítico susceptível de induzir a movimentação total ou parcial das vertentes. O enquadramento mediterrâneo deste contex to (que tem apenas em conta o efeito acumulado da precipitação!) leva-nos a estimar, ainda que com as devidas reservas, que este limiar crítico deverá ocorrer com forte probabilidade entre o final de Dezembro e o final de Janeiro. A formulação desta baliza cronológica admite as oscilações naturais do regime da precipitação (mensal mas principalmente diário) dado que entendemos que os $100 \%$ podem até nem ser atingidos bastando para tal que se verifique um episódio mais ou menos curto de precipitação bastante intensa. Devido ao reforço do efeito acumulado da precipitação, admitimos que este, ou outro cenário semelhante, possa antecipar (ou prolongar, se não se verificarem

(15) Na obra de HAMILTON (1997), WILSON refere que os valores críticos necessários para desencadear processos do tipo debris flow ou outros movimentos de vertente peliculares ou sub-superficiais varia em função da natureza climática. Esta ideia foi já referida por vários autores em estudos que procuram relações de causalidade, directas ou indirectas, entre as características da precipitação e a ocorência de movimentos de vertente, o que reforça a importância dos cuidados a ter na definição de limiares de precipitação. 


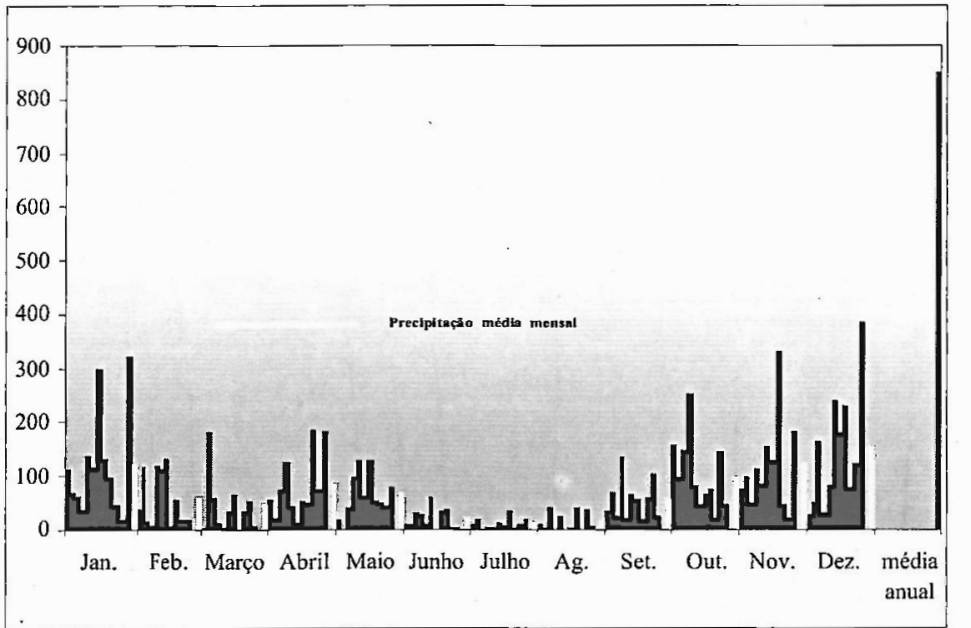

Fig. 13 - Precipitação média mensal (mm) registada na Régua (Estação de Avisos do Douro) entre Janeiro de $1990 \mathrm{e}$ Janeiro de 2001.

Fig. 14 - Precipitação (mm) registada em Vila Real entre Janeiro de 1961 e Dezembro de 1990.

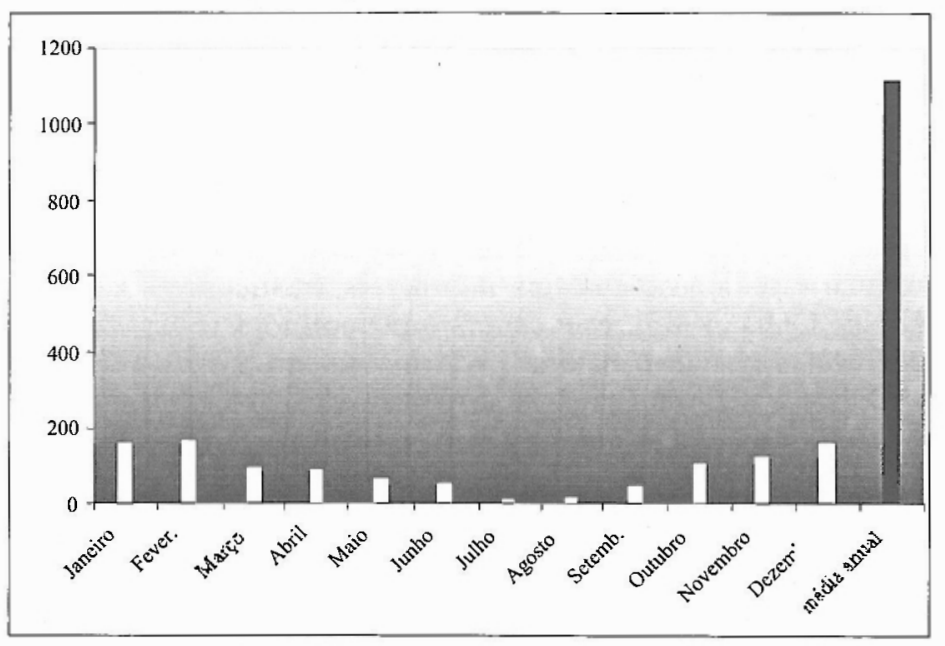

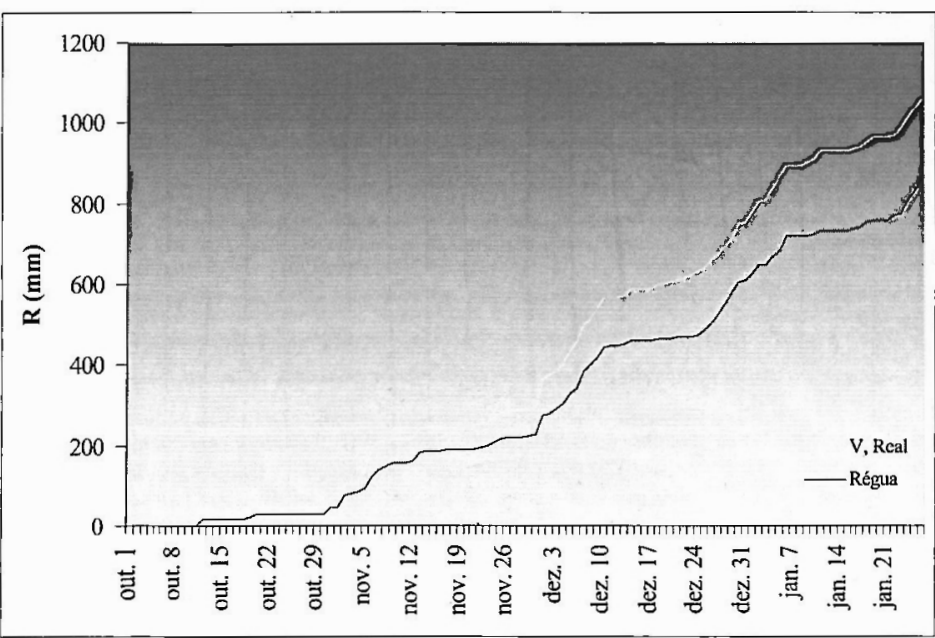

Fig. 15 - Comparação dos valores de precipitação registados nos 4 meses que antecederam os movimentos de vertente e a média para os períodos considerados em ambas a estaçōes.

OBS. - Os valores de Janeiro de 2001 apenas foram contabilizados até às $2 \mathrm{lb}$ do dia 26 


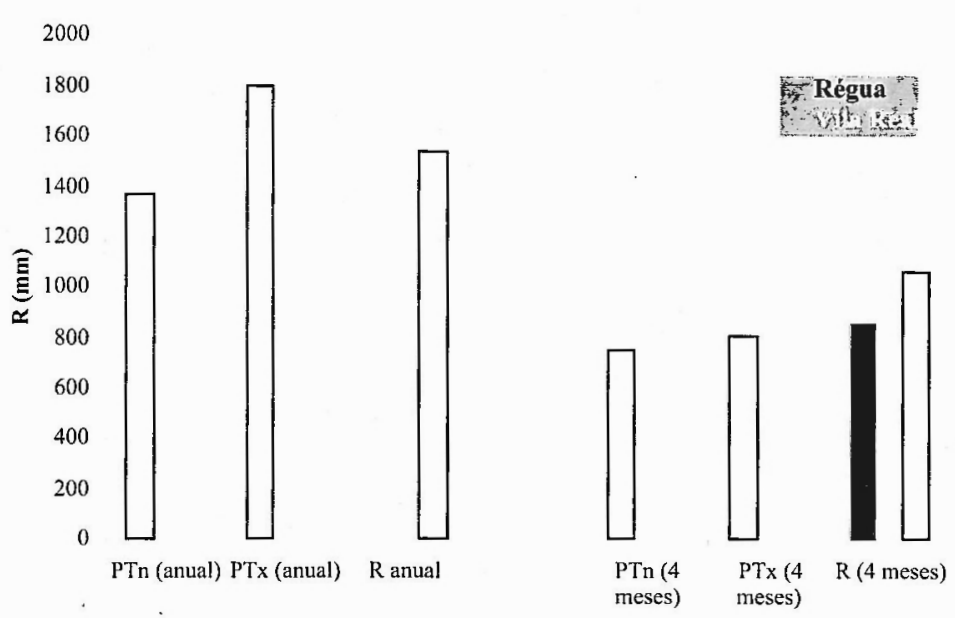

aqueles dados) o desencadear de situações de instabilidade nas vertentes, justificando-se deste modo a flutuação prevista.

Finalmente, a observação do quadro VI evidencia a reduzida importância individual dos quantitativos hídricos introduzidos nos sistemas-vertente durante o episódio pluvioso que antecedeu a ocorrência de dois movimentos mais importantes, já referidos. Tendo funcionado mais como reforço da precipitação acumulada, os registos de precipitação da série de cinco dias antecedentes deverá ter produzido um efeito de "gota de água" que denuncia o momento, o ponto de inflexão no balanço estabilidade/instabilidade das vertentes, que conduz à sua movimentação.

Quadro VI - Valores de precipitação registados na EAD para a série de dias pluviosos que antecedeu a ocorrência dos movimentos de Ariz e Alvações do Corgo.

\begin{tabular}{|c|c|}
\hline Evento & pluvioso \\
\hline DIA & $\mathbf{R}(\mathbf{m m})$ \\
22- Janeiro & 10,8 \\
23- Janeiro & 5,5 \\
24- Janeiro & 30,4 \\
25- Janeiro & 23,4 \\
23- Janeiro & 30,8 \\
Total & $\mathbf{1 0 0 , 9}$ \\
\hline
\end{tabular}

\section{Zonamento da probabilidade de ocorrência de movimentos de vertente}

Em fase inicial do trabalho apresentámos, detalhadamente, as metodologias utilizadas e salientámos os propósitos deste ensaio metodológico. Cabe agora recordar que a sequência e a articulação de processos postos em prática foram orientadas no sentido do zonamento de áreas com diferentes graus de exposição à ocorrência das três tipologias de movimentos vertente consideradas.
Elaborado no âmbito da UN-ISDR, o relatório ${ }^{(16)}$ de Genebra (1997) dedica o seu capítulo IV ao tema Landslides. Coordenado por ROBERT HAMILTON o grupo de trabalho responsável pela sua elaboração propõe um escalonamento das actividades de avaliação da estabilidade das vertentes em tarefas de "Tempo longo, Intermédio e Curto" destacando a importância de cada uma delas na aplicação ao estudo dos movimentos de vertente. Do reconhecimento e inventário de movimentos antigos à monitorização das vertentes para obtenção de dados em tempo "quase real", passando pela cartografia das áreas de maior susceptibilidade à ocorrência destes fenómenos - the onset of slope failure prone areas e pela previsão dos movimentos de vertente, a importância da complementaridade entre as diversas tarefas sobreleva a importância individual das mesmas. O mesmo documento conclui ainda que a natureza dos hazard maps permite enquadrá-los principalmente nas tarefas de prevenção e aviso de "Tempo longo" pelo facto de disponibilizarem importantes informações sobre áreas mais susceptíveis à ocorrência de movimentos de vertente e/ou que obriguem a medidas adicionais para mitigação dos seus efeitos.

A área em estudo (cfr. fig.1), caracteriza-se por um contexto morfo-estrutural e morfodinâmico onde a forte presença e histórica ocupação humanas têm vindo a incrementar os factores de risco, por um lado, porque interferem com a dinâmica cada vez menos (exclusivamente) natural das vertentes e, por outro lado, porque aumentam as vulnerabilidades dos espaços. Neste contexto enquadramos a importância dos documentos que resultam deste ensaio metodológico e na cultura de prevenção, previsão e aviso de "Tempo longo", inserimos a tentativa de zonamento

(16) Report on Early Warning Capabilities for Geological Hazards (R. HAMILTON, 1997). 
da probabilidade de ocorrência de movimentos de vertente que seguidamente se apresenta.

Organizados numa sequência que tornasse expedito o processamento da informação, os diferentes temas, parâmetros de terreno ou, se se preferir, os factores condicionantes da relação estabilidade/instabilidade nas vertentes, foram sendo sucessivamente cruzados com recurso ào comando "união" do ArcView GIS. Tratando-se de etapas intermédias, não nos preocupou a análise da tradução espacial, cartográfica, das novas tabelas de atributos resultantes do processo iterativo de união de temas, uma vez que só o tema resultante do último processo de união, reúne toda a informaçãonecessária para o zonamento das diferentes áreas. Depois de inserida uma nova coluna de valores na tabela de atributos do tema "união final" que resultou da fórmula de cálculo estabelecida em função dos critérios de ponderação específica, segundo uma metodologia que foi apresentada no início do trabalho, a tradução gráfica em shape files (shp), da informação numérica - dBase files (dbf), do tema "união final", concretamente, da coluna de valores onde foi inserida a fórmula de cálculo, resultou na elaboração de mapas paramétricos intercalares. Estes documentos cartográficos permitiram individualizar áreas com diferentes graus de exposição às tipologias de movimentos de vertente consideradas (fig. $17 \mathrm{~A}, \mathrm{~B} \mathrm{e}$
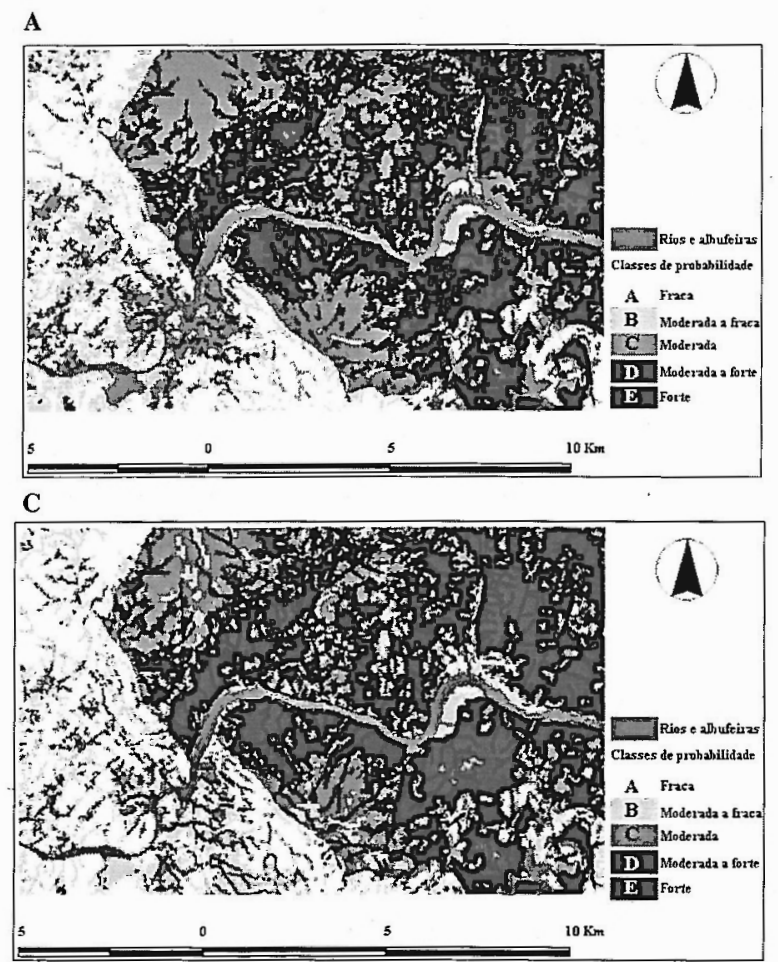

C). Trabalhadas a uma escala que não seria, obviamente, possível de apresentar neste trabalho, os mapas intercalares seriam também ponderados em função da gravidade das ameaças que as diferentes tipologias de movimentos potencialmente representam, ou seja, em função dos danos esperados; o resultado da ponderação efectuada, em termos de operações no sistema significa a introdução de uma nova coluna na tabela de atributos do tema "união final" com a nova fórmula de cálculo estabelecida. $O$ resultado gráfico desta operação é apresentado na figura 17-D - mapa de síntese ponderado do grau de exposição das vertentes a estes fenómenos ou, se se preferir, o somatório dinâmico das susceptibilidades (cfr. fig.3). Optámos pelo somatório de valores preterindo o produto factorial, por um lado, porque esta modalidade anularia o valor de hazard bastando para tal que apenas um dos factores fosse nulo, por outro lado, porque pensamos que o somatório de pesos específicos se ajusta melhor ao processo de análise multicritério em ambiente SIG para avaliação e cartografia de hazards.

Partindo da análise dos 441 movimentos de vertente registados e classificados em três tipologias, procurámos identificar os padrões da distribuição dos movimentos. A determinação da probabilidade de ocorrência determinada em função das correlações identificadas,
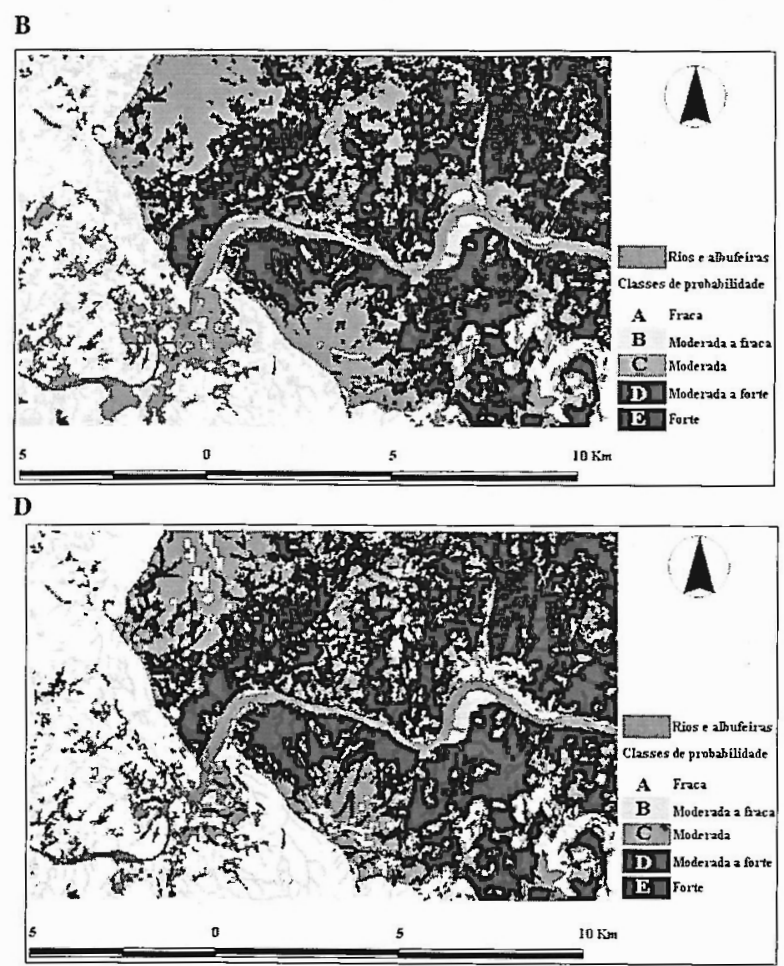

Fig. 17-Zonamento do grau de exposição das vertentes à probabilidade de ocorrência de movimentos de vertente. A - tipo G1; $\quad$ B - tipo G2;

C - tipo G3 e D-Mapa-síntese de hazards. 
com a devida prudência, pode ser aplicada a áreas que apresentem contextos semelhantes (INTERNATIONAL UNION OF GEOLOGICAL SCIENCES IUGS, 1997; FELL \& HARTFORD, 1997 e VAN WESTEN, 1998). Neste caso, a extrapolação analítica foi aplicada à área abrangida pela folha $126 \mathrm{da}$ Carta Militar de Portugal onde não efectuámos registos de movimentos de vertente, seja porque não existem mesmo, seja porque se trata de áreas que não foram percorridas, mas que apresentam quadros semelhantes ao nível da articulação entre as variáveis consideradas, morfo-estrutura, Hidrografia, Biogeografia, actividades antrópicas e quadro meteorológico e climático. As restantes áreas da folha da Carta Militar de Portugal já referida, apresentam padrões de zonamento das probabilidades de ocorrência de movimentos de vertente claramente associados aos factores que denunciaram correlações positivas mais fortes com a distribuição dos movimentos. Assim, há maiores probabilidades de ocorrência de movimentos do tipo G1 ou de G2 (cfr. fig. $17 \mathrm{D}$ e quadro VII) em contextos basicamente semelhantes que diferem essencialmente na morfometria dos movimentos, no volume dos depósitos resultantes da acumulação do material deslocado. Os movimentos considerados como G1 parecem ter um

\section{Conclusão}

Constituindouma das muitas combinações possíveis para análise e avaliação multicritério efectuada em ambiente SIG, o ensaio metodológico para avaliação quantitativa e qualitativa do hazard, não dispensa a integração de dados de fontes diversas. A contribuição de cada um dos factores não pode ser lida apenas num quadro em que o resultado é igual à soma estática das partes, dado que para além de não ser possível parametrizar todas as variáveis intervenientes nestes complexos processos que caracterizam a evolução de vertentes, o quadro onde intervêm sendo interactivo e dinâmico, pressupõe influências mútuas que nem sempre se conseguemidentificarou quantificar. Por outro lado, este esforço de aproximação requer, desde logo, complementaridade com outras escalas de análise, designadamente de maior pormenor, que disponibilizem dados cujo tratamento possa ser traduzido por tarefas de aviso e prevenção de "tempo curto", mas requer também a comparação com os resultados de outras metodologias, designadamente estatísticas e morfo-cinemáticas (campos onde está já em curso a sequência destas investigações) de modo a que a validação dos modelos permita um

\begin{tabular}{|c|c|c|c|c|}
\hline & Fartares cond. Mavimentos & Gi (338) & G2(83) & $3(20)$ \\
\hline & Hidrografiza & $20,70 \%$ & $28,90 \%$ & $55 \%$ \\
\hline Quadro VII - Quadro-síntese das & Fracturazăo & $2,40 \%$ & a & 0 \\
\hline $\begin{array}{l}\text { principais influências das } \\
\text { condicionantes hidrográficas, }\end{array}$ & Littologia & $\operatorname{cxg}(83 \%)$ & $\operatorname{cxg}(92 \%\}$ & $\operatorname{CxG}(85 \%)$ \\
\hline morfológicas, estruturais e & Declive & $24-32^{\circ}(36 \%)$ e $16-24^{4}(26 \%)$ & $16-24^{\circ}(40 \%)<24-32^{\circ}(34 \%)$ & $24-32^{\circ}(55 \%)$ \\
\hline $\begin{array}{r}\text { biogeográficas para a distribuição } \\
\text { dos movimentos de vertente na }\end{array}$ & Equosicä́ & $\mathrm{E}(17 \%), \mathrm{Ne}(15 \%)$ e plano $(14,5 \%)$ & $E(17 \%)$. Ne $(15 \%)$ e plano $(15 \%)$ & $\mathrm{N}_{\mathrm{e}}(25 \%), \mathrm{E}(15 \%)$ \& Sw $(15 \%)$ \\
\hline área em estudo & Oruparzäo e uso do solo & Socalcos $(73 \%)$ & Socalcos $(81 \%)$ & Socalcos $(75 \%)$ e Resuosas $(15 \%)$ \\
\hline
\end{tabular}

elevado grau de associação com contextos caracterizados pela existência de depósitos, mantos de alteração ou material detrítico com transporte antrópico, com espessuras na ordem dos 1,5 metros, pouco compactados e assentes sobre a litologia do CXG, vertentes com declives compreendidos entre 16 e $32^{\circ}$, expostas a $E$ e NE, e áreas de socalcos designadamente os sectores mais aplanados sem exposição definida. Para o grupo referido como $\mathrm{G} 3$ o quadro mais provável de oçorrência conjuga a existência de pequenos canais com uma combinação semelhante da componente morfo-estrutural referida para os grupos G1 e G2 a que se acrescentam as vertentes expostas a SW e as áreas ocupadas por resinosas, deixando de ter significado as áreas aplanadas. acréscimo significativo nas tarefas de previsão no espaço e no tempo, com ganhos claros para as populações uma vez que daí resultam ganhos acrescidos em termos de factores de segurança diminuindo, por outro lado, as vulnerabilidades.

\section{Agradecimentos}

Não podemos deixar de destacar, ainda que em breve nota, o contributo importante da Comissão de Coordenação da Região Norte (CCRN) na pessoa do Sr. Eng. Figueiredo Pereira que nos atendeu com elevada distinção sempre que a necessidade de mais informação, quase sempre fornecida em suporte digital, 
nos conduzia inevitavelmente ao seu contacto. Ao Centro Nacional de Informação Geográfica (CNIG) agradecemos o disponibilizar de informação ortofotogramétrica e cartografia de base em formato vectorial, documentos importantes para a prossecução dos objectivos do trabalho. É, ainda, com reconhecida gratidão que referimos também a importância do apoio que nos tem sido dado, desde há já alguns anos, pela Câmara Municipal de Vila Flôr a quem agradecemos, na pessoa do seu Presidente, o Dr. Artur Pimentel, o indispensável apoio logístico.

Referências bibliográficas

ANTUNES DO CARMO, J. S. (1990) - Efeitos hidrodinâmicos resultants de deslizamentos de encostas em albufeiras. Modelação a duas dimensões horizontais. Dissertação de Mestrado, Coimbra, $125 \mathrm{p}$.

BARREDO, J., BENAVIDES, A., HERVÁS, J., LOMOSCHITZ, A. \& VAN WESTEN, C. (2000) - "Landslide hazard assessement using GIS and multicriteria evaluation techniques in the Tirajana basin, Gran Canaria Island". European Commission on Environment and Geo-Information Unit, Space Applications Institute.

BATEIRA, C. (2001) - Movimentos de vertente no NW de Portugal, Susceptibilidade Geomorfológica e Sistemas de Informação Geográfica. Dissertação de Doutoramento, Porto, 447 p.

BROMHEAD, E. N., \& IBSEN, M-L. (1997) - "Land-use and climate-change impacts on landslide hazards in SE Britain". Cruden \& Fell (eds.) Landslide Risk Assessment, Balkema, Roterdão, 165-176.

BRUNSDEN, D. (1984) - "Mudslides". Brunsden \& Prior (eds.) Slope Instability, John Wiley \& Sons, Chichester, 363-418.

BURNS, S. (1999) - Engineering geology and relative satbility of the southern half of Newell Creek Canyion, Oregon City, Oregon. Dissertação de Mestrado, Portland, 156 p.

CUNHA, L. \& ROCHA, R. (1997) - "Ensino da Geografia e riscos naturais. Reflexões a propósito de um mapa de riscos naturais do vale de Coselhas (Coimbra)". Cadernos de Geografia, 16, 25-38.

DIKAU, R., BRUNSDEN, D., SCHROTT, L., \& IBSEN, M-L. (1996) - Landslide Recognition; Identification, Movement and Causes. John Wiley \& Sons, Chichester,

EINSTEIN, H. (1997) - "Landslide risk - Systematic approaches to assessment and management". Cruden \& Fell (eds.) Landslide Risk Assessment, Balkema, Roterdão, 25-50.

ELO, O. (1994) - "Message". In Singh (eds.) Disasters, Environment and Development. Procedings of International Geographical Union Seminar, New Delhi, 5-7.

FELL, R. \& HARTFORD (1997) - Landslide risk management. Cruden \& Fell (eds.) Landslide Risk Assessment. Balkema, Roterdão, 51-110.
FERRER-GIJÓN, M. (1987) - "Deslizamientos, Desprendimientos, Flujos y Avalanchas". In Carcedo Ayala, F., Riesgos Geologicos, Instituto Geológico y Minero de España, 175-192.

GARLAND, G. \& OLIVIER, M. (1993) - "Predicting landslides from rainfall in a humid, sub-tropical region". Geomorphology, $8,165-173$.

HAMILTON, R. (1997) - "Report on Early Warning Capabilities for Geological Hazards", IDNDR, Geneve.

HANSEN, M. J. (1984) - "Strategies for classification of landslides". Brunsden \& Prior (eds.) Slope Instability, John Wiley \& Sons, Chichester, 1-25.

HUNGR, O. (1997) - "Some methods of landslide hazard intensity mapping". Cruden \& Fell (eds.) Landslide Risk Assessement, Balkema, Roterdão, 215-226.

HUTCHINSON, J. (1968) - "Mass movement". Fairbridge, R. (eds.), Encyclopedia of Geomorphology, Reinhold, New York, 688-695.

HUTCHINSON, J. (1988) - "General report: Morphological and geothecnical parameters of landslides in relation to geology and hiydrogeology". Bonnard, C. (eds.) Landslides, Proceedings on the 5th International Symposium on Landslides. Lausanne, vol. I, Balkema, Rotterdam, 3-35.

IUGS (1997) - "Quantitative risk assessement for slopes and landslides - the state of the art". Cruden \& Fell (eds.) Landslide Risk Assessment, Balkema, Roterdão, 3-12.

MÉNEROUd, J. P. (1983) - "Rélations entre la pluviosité et le déclenchement de mouvements de terrain". Bull. Liaison Lab. Pet. Ch, 124, 89-100.

MOSTYN, G.R. \& FELL, R. (1997) - "Quantitative and semiquantitative estimation of the probability of landsliding". Cruden \& Fell (eds.) Landslide Risk Assessment, Balkema, Roterdão, 297-316.

REBELO,F. (1981)- "A acção humana como causa de desabamentos e deslizamentos". Separata de Biblos, LVII, 629-644.

REBELO, F. (1995) - "Os conceitos de Risco, Perigo e Crise e a sua aplicação ao estudo đos grandes incêndios florestais". Biblos, LXXI, 510-527.

REBELO, F. (1997) - "Riscos geomorfológicos na área a norte de Lisboa". Notas, Nótícias e Recensões, Cademos de Geografia, $16,125-129$.

REBELO, F. (2001) - Riscos naturais e acção antrópica. Imprensa da Universidade, Coimbra.

ROBERDS, W. J., HO, K. \& LEUNG, K.W. (1997) - "An integrated methodology for risk assessment and risk management for development below potential natural terrain Iandslides". Cruden \& Fell (eds.) Landslide Risk Assessment, Balkema, Roterdão, 333-346.

SANTOS, J.G. (1997) - "Instabilidade de vertentes e riscos de movimentos de terreno; o exemplo da área de Vila SecaLamas (a Sul de Coimbra)". Territorium, 4, 79-98. 
SANTOS, J. G., CUNHA, L. \& FERREIRA, R. (...) - "Environmental marginality and natural disasters; a case study at Régua (Portugal) in the Douro wine region". Dynamics of Marginal and Critical Regions. Intemational Geographical Union, Ashgate, Aldershot, United Kingdom, (em publicação).

TAVARES, A. (1999) - Condicionantes fisicas ao planeamento, análise da susceptibilidade noespaço do concelho de Coimbra. Dissertação de Doutoramento, Coimbra, 346 p.

TAVARES, A. (2001) - "Instabilidade de vertentes e Planeamento municipal; precaução ou minimização?" Resumos do II Seminário de Geologia Ambientai, Desprendimentos de Terra e Estabilidade de Vertentes, Braga, 22-28.

VARNES, D. (1978) - "Slope movement Types and Processes". Schuster \& Krizek (eds.) Landslides, Analysis and Control, Transporiation Research Board Special Report, 176, Washington, 11-13.
VANWESTEN, C. J. (1998) - "Hazard, vulnerability and risk analisys. Prediction of occurrence of slope instability phenomena through GIS based hazard zonation". International Institute for Aerospace Survey and Earth Sciences (ITC), Enschede.

ZÊZERE, J. L. (1997) - Movimentos de vertente e perigosidade geomorfológica na Região a Norte de Lisboa. Dissertação de Doutoramento em Geografia Física, Lisboa, 575 p.

ZÊZERE, J. L. (2000)- “A classificação dos movimentos de vertente, tipologia, actividade e morfologia". Apontamentos de Geografia, série: Investigação, 1-29.

ZÊZZERE, J. L. (2001) - "Dinâmica de vertentes e perigosidade geomorfológica na área metropolitana de Lisboa". Resumos do II Seminário de Geologia Ambiental, Desprendimentos de Terra e Estabilidade de Vertentes, Braga, 29-40.

ZÊZERE, J. L. E RODRIGUES, M. L. (1991) - "Estudo e prevenção de riscos naturais - contributo da Geografia Física". Actas do $I^{\circ}$ Congresso de Geografia Portuguesa, Lisboa, 445-455. 
